\title{
Massive comparative genomic analysis reveals convergent evolution of specialized bacteria Vicky Merhej ${ }^{1}$, Manuela Royer-Carenzi ${ }^{2}$, Pierre Pontarotti ${ }^{2}$ and Didier Raoult*1
}

Address: ${ }^{1}$ Unit for Research on Emergent and Tropical Infectious Diseases (URMITE), CNRS-IRD UMR 6236 IFR48, Faculty of Medicine, University of the Mediterranean, Marseilles, France and 2Evolutionary biology and modeling, LATP UMR CNRS 6632 FR 3098 IFR 48, University of Provence, Marseilles, France

Email: Vicky Merhej - vicky_merhej@hotmail.com; Manuela Royer-Carenzi - royermanuela@yahoo.fr; Pierre Pontarotti - Pierre.Pontarotti@univ-provence.fr; Didier Raoult* - didier.raoult@gmail.com

* Corresponding author

Published: 10 April 2009

Biology Direct 2009, 4:13 doi:10.1186/1745-6150-4-13

This article is available from: http://www.biology-direct.com/content/4/I/I3

This is an Open Access article distributed under the terms of the Creative Commons Attribution License (http://creativecommons.org/licenses/by/2.0), which permits unrestricted use, distribution, and reproduction in any medium, provided the original work is properly cited.

\begin{abstract}
Background: Genome size and gene content in bacteria are associated with their lifestyles. Obligate intracellular bacteria (i.e., mutualists and parasites) have small genomes that derived from larger free-living bacterial ancestors; however, the different steps of bacterial specialization from free-living to intracellular lifestyle have not been studied comprehensively. The growing number of available sequenced genomes makes it possible to perform a statistical comparative analysis of 317 genomes from bacteria with different lifestyles.
\end{abstract}

Results: Compared to free-living bacteria, host-dependent bacteria exhibit fewer rRNA genes, more split rRNA operons and fewer transcriptional regulators, linked to slower growth rates. We found a function-dependent and non-random loss of the same 100 orthologous genes in all obligate intracellular bacteria. Thus, we showed that obligate intracellular bacteria from different phyla are converging according to their lifestyle. Their specialization is an irreversible phenomenon characterized by translation modification and massive gene loss, including the loss of transcriptional regulators. Although both mutualists and parasites converge by genome reduction, these obligate intracellular bacteria have lost distinct sets of genes in the context of their specific host associations: mutualists have significantly more genes that enable nutrient provisioning whereas parasites have genes that encode Types II, IV, and VI secretion pathways.

Conclusion: Our findings suggest that gene loss, rather than acquisition of virulence factors, has been a driving force in the adaptation of parasites to eukaryotic cells. This comparative genomic analysis helps to explore the strategies by which obligate intracellular genomes specialize to particular host-associations and contributes to advance our knowledge about the mechanisms of bacterial evolution.

Reviewers: This article was reviewed by Eugene V. Koonin, Nicolas Galtier, and Jeremy Selengut. 


\section{Background}

Genome size in bacteria is extremely variable, ranging from 0.16 megabases $(\mathrm{Mb})$ in Carsonella ruddii [1] to approximately $10 \mathrm{Mb}$ in Burkholderia xenovorans [2]. Genome size and gene repertoire can increase through gene acquisition, i.e. DNA transfer and gene duplication, and conversely, decrease by deletion $[3,4]$. Genome analyses of obligate intracellular, including mutualistic and parasitic organisms, showed that these bacteria have small genomes that are derived from larger free-living bacterial ancestors [5-8]. This reductive evolution has been associated with metabolic parasitism or mutualism, during adaptation to an intracellular habitat $[7,9,10]$. The analysis of gene contents of fully sequenced genomes provided insights into the relationship between the ecology and genome evolution of studied bacteria [11-13]. The growing number of available bacterial genomes makes it possible to perform a comparative genomic analysis of 317 genomes from bacteria with different lifestyles. Bacteria were classified according to their lifestyle as host-dependent (125 bacteria) and free-living (192 bacteria). Among host-dependent bacteria, 85 were identified as facultative host-associated (extracellular or intracellular), and 40 bacteria (27 parasites and 13 mutualists) that are specialized to an obligate intracellular lifestyle (Figure 1 and Additional file 1) $[14,15]$. We determined the phylogenetic profile of all studied bacteria with respect to their orthologous genes content (COGs). We compared the 317 genomes with respect to their genome size, $\mathrm{G}+\mathrm{C}$ content, ribosomal RNA operons (rRNA), and orthologous gene composition. We identified genomic features typical of each way of life, highlighting the significant differences in the genomic repertoires between obligate intracellular and free-living bacteria, as well as differences between mutualistic and parasitic bacteria. Our comparative analysis sheds light on the process of evolution from the larger genomes of ancestral species to the specialized smaller genomes of obligate intracellular bacteria, and reveals the genetic basis of their specialization to an intracellular lifestyle. We demonstrate that there is a convergent evolution of obligate intracellular bacteria from different phyla.

\section{Results and discussion Genomic features and lifestyle}

Host-dependent bacteria typically have a smaller genome size and fewer genes compared to their close relatives in the same phylum (Additional file 2). Linear regression analysis showed strong positive correlations between genome size and GC content $\left(R^{2}=0.376, F_{1,315}=190, p<\right.$ $\left.10^{-6}\right)$ and between genome size and gene number $\left(R^{2}=\right.$ $\left.0.976, F_{1,315}=12900, p<10^{-6}\right)$. Indeed, the trend towards genome reduction holds true for all host-dependent bacteria and the maximum reduction has been noted for the obligate intracellular bacteria (unpaired Student's t-test, all $p<10^{-2}$, Figure 2). The AT mutational bias may be explained by the impairment of the reparation system $[16,17]$ or by metabolic reasons $[18,19]$. Genome size, number of genes and GC content of bacteria diminish during the specialization to an intracellular lifestyle, indicating a continual selective pressure for a minimal genome [20]. One explanation is the intracellular habitat that limits the capacity for gene acquisition by lateral gene transfer (LGT) [13,21-23]. Other reasons include gene loss with increased adaptation to the host [10,24]. Once restricted to the intracellular environment, the opportunities for LGT are diminished, so the likelihood of reversal is low, and the possibility of ever acquiring the functions needed to live in a less specialized environment successfully (i.e. in competition with better equipped organisms) is small. Indeed, the balance between acquired and lost genes is in favour of genome reduction and irreversible massive gene decay implies that specialization to an intracellular lifestyle is a one-way road.

\section{Gene repertoire and lifestyle}

Using the Reverse PSI-Blast program [25], we were able to assign, on average, $71.03 \pm 7.73 \%$ of the ORFs (Open Reading Frame) in any genome to a COG functional category. Thus we have characterized the large majority of the repertoire of each bacterium, knowing that $\approx 15$ to $20 \%$ of the predicted genes in every genome sequenced so far, is species-specific [26]. The principal coordinate (PCO) analysis of COG content distances, calculated on the basis of the presence or absence of a COG, showed that bacteria from the same lifestyle tend to be clustered together (multivariate analysis variance, $p<10^{-6}$, Figure 3) [27-31]. The difference in genome contents reflects a differential gene loss, with a greater extent of loss in obligate intracellular bacteria. To identify function repertoires related to each lifestyle, we compared the number of genes assigned to each COG in the host-dependent genomes with that in free-living bacteria. Genes involved in DNA replication, recombination and repair, RNA processing and modification, translation, post-translational modification, and intracellular trafficking and secretion significantly increased their representation in all the host-dependent compared to free-living bacteria. In contrast, genes belonging to the functional categories of transcription, defence mechanisms, transport and metabolism of amino acids, inorganic ions, and secondary metabolites significantly decreased in their percentage of genome representation (paired Student's t-test, $p<10^{-2}$, Table 1). Bacteria display different functional gene inventories, with functions specific to their ecological niche.

Based upon the assumption that COGs conserved in the reduced genomes of host-dependent bacteria from different phyla are likely to be essential and therefore result from a vertical transmission, we searched for the essential COGs. We found that only 35 COGs were conserved in all 


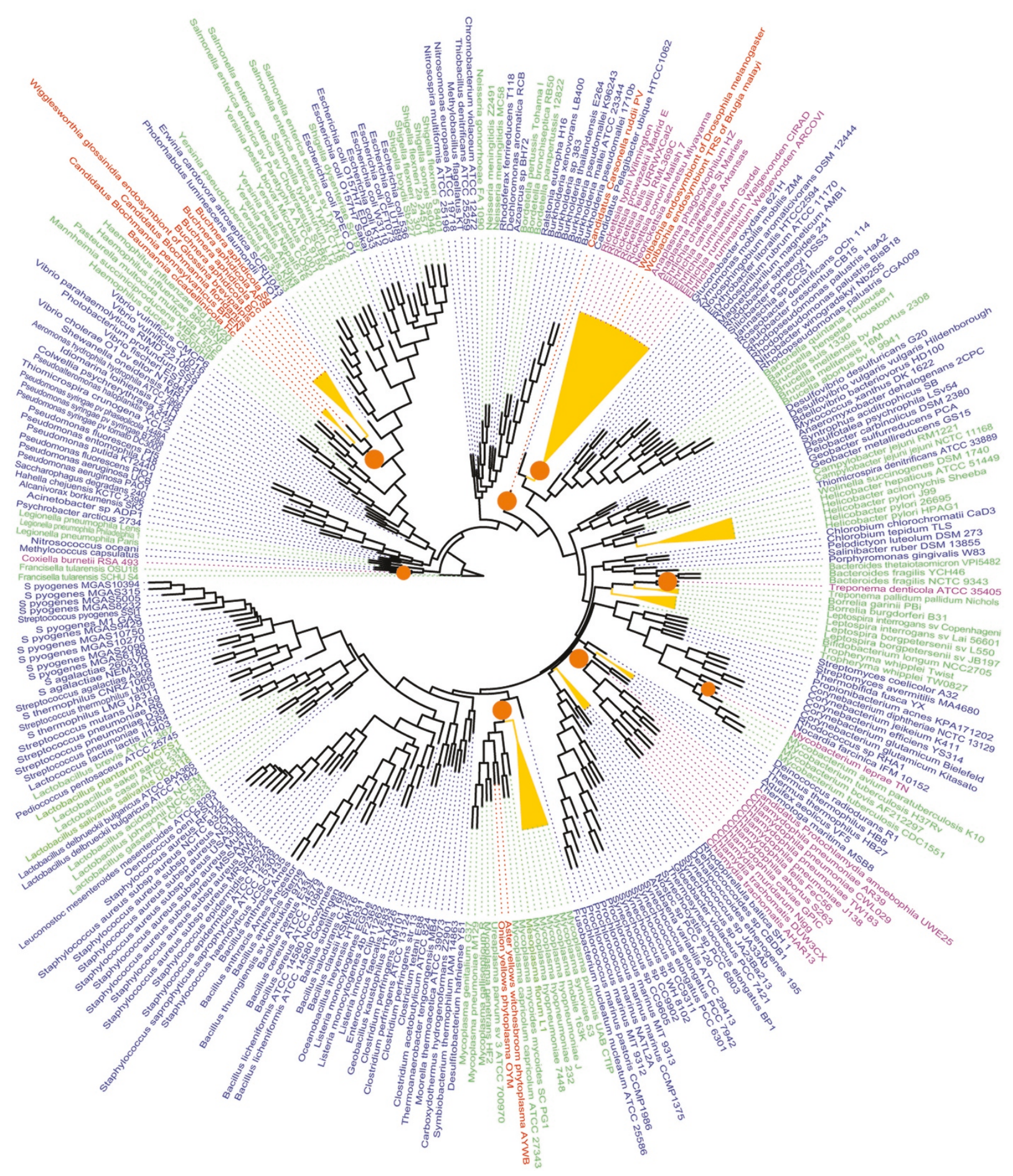

Figure I

Phylogenetic relationships and converging evolution. The phylogenetic unrooted tree was constructed on the basis of the I6S rRNA gene sequences from the 317 bacteria using the neighbour-joining method [15] within the Phylip package [14]. The tree was visualized using FigTree software http://tree.bio.ed.ac.uk/software/figtree/. Organisms are colored according to lifestyle: red for mutualists, purple for parasitic, green for facultative host-dependent, and blue for free-living bacteria. The events of split rRNA operons (yellow triangles) and loss of the 100 genes set (orange circles) are coincident with the location of the host-dependent bacteria in different phyla. 


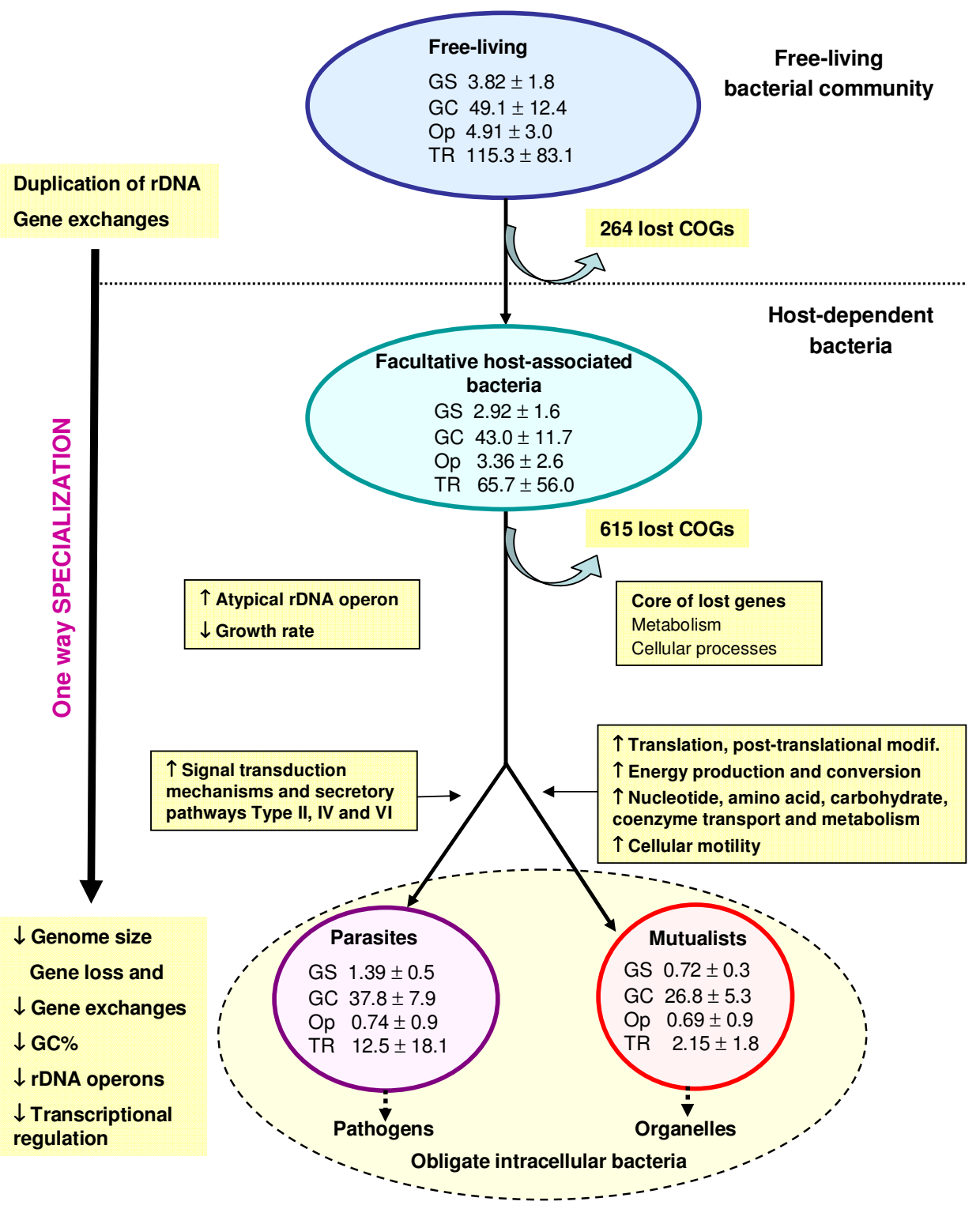

Figure 2

Proposed scenario for genome evolution and specialization. Model of evolution involving 3 steps en route to specialization to an intracellular lifestyle. The different steps correspond to the different levels of dependency to eukaryotic cells, the minimum is for the free-living bacteria and the maximum is for obligate intracellular bacteria. Each Step corresponds to a bacterial community sharing common habitat and relationship with eukaryotic cells. Bacterial specialization to an intracellular lifestyle is characterized by gene loss including transcriptional regulators and rRNA operons. Free-living promiscuous bacteria have large genomes because of a high level of gene importation. They also have a large number of rRNA operons. Obligate intracellular bacteria have reduced genomes with few rRNA operons and transcription regulators. When bacterial lineages make the transition from free-living to permanent associations with hosts, they undergo a major loss of genes. Restriction to an intracellular environment limits the opportunity to acquire foreign genes from other bacteria therefore the balance between acquired and lost genes in specialized bacteria is in favour of genome reduction. Irreversible massive gene decay implies that specialization to an intracellular lifestyle is a one-way road. Differential gene loss is noted in mutualistic and parasitic bacterial groups. Data in circles represent the mean ( \pm s.d.) of genome size in megabases (GS), GC content (GC), rRNA operon (Op), and number of genes assigned to transcriptional regulation (TR) in each bacterial community. Numbers on the arrows represent the average number of lost genes \pm the standard error in order to compute confidence intervals for the estimated loss ratio (proportion of genes lost with respect to the whole number of genes present at least in one bacterium). 


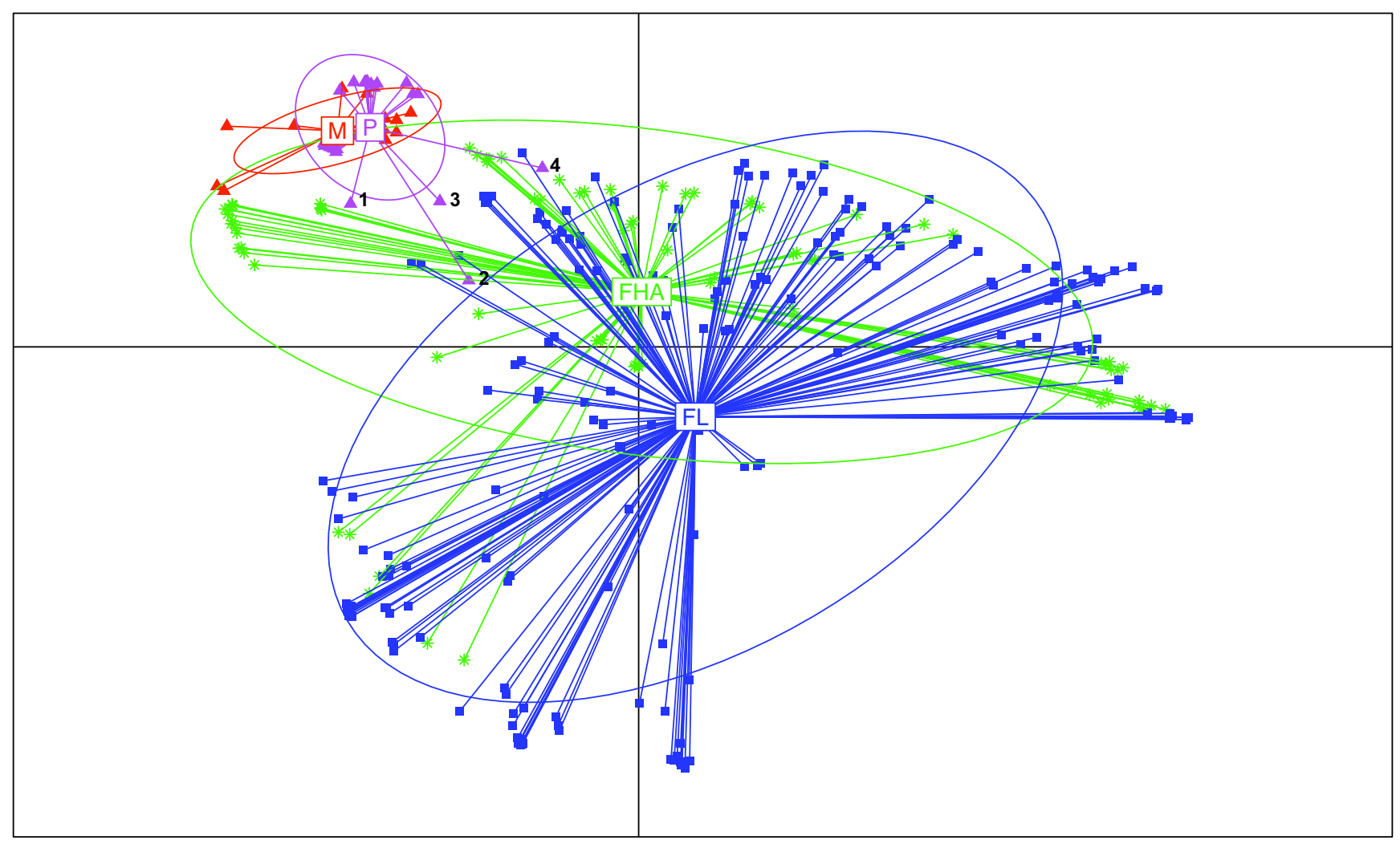

\section{Figure 3}

Plot of the first Principal Coordinate Analysis (PCO) axis of COGs content distances. Multivariate analysis graphics of the COGs content of all studied bacteria using $\mathrm{R}$ ade 4 package. Each bacterium is represented by a symbol linked by a line to the gravity center of the group it belongs to $(M$, obligate intracellular mutualists, red triangles; $P$, obligate intracellular parasites, purple triangles; FHA, facultative host- associated, green asterisks; and FL, free-living, blue squares). An ellipse was also drawn for each class, which size increases with the coordinates' dispersion in the class. It is computed such that it would contain $68 \%$ of the individuals in the studied class if the distribution were Gaussian. Otherwise, it is just a way to compare dispersion between classes. I represents Treponema pallidum; 2 represents Mycobacterium leprae; 3 represents Candidatus Protochlamydia amoebophila UWE25; 4 represents Coxiella burnetii. These species with larger genome sizes and gene contents than the other obligate intracellular bacteria undergo reductive evolution [28,30]. Some of these bacteria have high number of pseudogenes $[27,29,3 \mathrm{I}]$. The presence of pseudogenes displays an ongoing process of gene degradation.

317 bacteria. The size of the essential COGs set could be underestimated due to the small genome size of Carsonella ruddii $(160 \mathrm{~Kb})$. Indeed, 100 COGs were found conserved in $99 \%$ of the bacteria (Table 2). These genes are likely to be essential and are good candidates for inclusion in the minimal gene set. Like other minimal gene sets [32-37], this set consisted mainly of genes encoding for the DNA replication and translation system components, genes that preserve the integrity of their product, such as genes encoding proteins involved in DNA repair, protein degradation and proofreading, chaperone-like proteins, and a few basal components of the transcription system (Table 3 , Chi-squared test for independence $\chi^{2}=485.5, d f=3, p$ $\left.<10^{-6}\right)$. Altogether, the essential genes that are conserved in all genomes become proportionally more important in small reduced genomes than in large genomes.

\section{Convergent reductive evolution of obligate intracellular bacteria}

When considering the presence or absence of a COG, we found that facultative host-associated bacteria have 264 COGs less than the free-living bacteria and 615 COGs more than the obligate intracellular bacteria. The differences observed between the different bacterial communities correspond to the COGs lost in relation with the level of host-dependency (mean loss ratio $\pm \mathrm{sd}$ : $6 \pm 11 \%$ and 16 $\pm 17 \%$, Figure 2 ). Thus, on the first level of dependency (i.e., facultative host-associated lifestyle) bacteria have already lost 264 COGs. To achieve the second level of host-dependency (i.e., obligate intracellular lifestyle) bacteria undergo an additional loss of 615 COGs significantly greater than the previous loss (unpaired Student's t-test, $p$ $<10^{-6}$ ). Moreover, the number of genes assigned to each 
Table I: Distribution of the protein-coding genes of host-dependent and free-living bacteria in COG functional categories

\begin{tabular}{|c|c|c|c|c|c|c|}
\hline COG functional categories & Code & OI $(n=40)$ & FHA $(n=85)$ & HD (n = I25) & FL $(n=192)$ & HD vs. FL \\
\hline (a) Gene count Mean +/- s.d. & & & & & & $p$-value* \\
\hline Chromatine structure and dynamics & B & $0.28 \pm 0.45$ & $0.44 \pm 1.07$ & $0.38 \pm 0.92$ & $1.16 \pm 1.28$ & 0.4982 \\
\hline Replication, recombination and repair & $\mathrm{L}$ & $56.78 \pm 26.49$ & $161.58 \pm 171.99$ & $128.04 \pm 150.56$ & $|4| .23 \pm 55.84$ & 0.3035 \\
\hline Transcription & $\mathrm{K}$ & $23.70 \pm 10.23$ & $105.65 \pm 74.89$ & $79.42 \pm 72.84$ & $163.82 \pm 99.52$ & 0.0000 \\
\hline RNA processing and modification & A & $0.70 \pm 1.26$ & $1.20 \pm 2.09$ & $1.04 \pm 1.87$ & $1.11 \pm 1.87$ & 0.9290 \\
\hline Translation, ribosomal structure and biogenesis & $\mathrm{J}$ & $116.68 \pm 13.97$ & $143.42 \pm 25.75$ & $134.86 \pm 25.83$ & $157.62 \pm 19.27$ & 0.0000 \\
\hline $\begin{array}{l}\text { Posttranslational modification, protein turnover, } \\
\text { chaperones }\end{array}$ & O & $39.08 \pm 10.84$ & $74.60 \pm 41.27$ & $63.23 \pm 38.31$ & $94.13 \pm 39.75$ & 0.0000 \\
\hline $\begin{array}{l}\text { Intracellular trafficking, secretion, and vesicular } \\
\text { transport }\end{array}$ & $U$ & $29.68 \pm 10.05$ & $59.62 \pm 44.82$ & $50.04 \pm 39.86$ & $63.77 \pm 44.54$ & 0.0002 \\
\hline Signal transduction mechanisms & $\mathrm{T}$ & $10.48 \pm 8.45$ & $56.65 \pm 41.04$ & $41.87 \pm 40.39$ & $103.67 \pm 67.24$ & 0.0001 \\
\hline $\begin{array}{l}\text { Cell cycle control, cell division, chromosome } \\
\text { partitioning }\end{array}$ & $\mathrm{D}$ & $11.20 \pm 5.52$ & $21.96 \pm 9.96$ & $18.52 \pm 10.11$ & $25.72 \pm 7.73$ & 0.0000 \\
\hline Defense mechanisms & $\mathrm{V}$ & $2.60 \pm 4.32$ & $20.56 \pm 13.81$ & $14.82 \pm 14.35$ & $29.46 \pm 14.94$ & 0.0000 \\
\hline Cell wall/membrane/envelope biogenesis & M & $39.10 \pm 22.84$ & $110.27 \pm 65.03$ & $87.50 \pm 64.34$ & $|30.06 \pm 59.9|$ & 0.0000 \\
\hline Cell motility & $\mathrm{N}$ & $8.23 \pm 10.53$ & $44.73 \pm 44.12$ & $33.05 \pm 40.57$ & $53.24 \pm 51.60$ & 0.0172 \\
\hline Cytoskeleton & Z & $0.08 \pm 0.47$ & $0.28 \pm 1.09$ & $0.22 \pm 0.94$ & $0.24 \pm 0.78$ & 0.8927 \\
\hline Nucleotide transport and metabolism & $\mathrm{F}$ & $26.70 \pm 10.47$ & $54.55 \pm 19.22$ & $45.64 \pm 21.33$ & $69.52 \pm 15.52$ & 0.0000 \\
\hline Amino acid transport and metabolism & $\mathrm{E}$ & $39.65 \pm 20.39$ & $152.06 \pm 108.15$ & $116.09 \pm 104.05$ & $213.71 \pm 106.02$ & 0.0000 \\
\hline Carbohydrate transport and metabolism & G & $24.05 \pm 10.89$ & $112.52 \pm 86.46$ & $84.21 \pm 82.57$ & $132.33 \pm 70.07$ & 0.0000 \\
\hline Lipid transport and metabolism & I & $26.15 \pm 11.18$ & $58.54 \pm 45.94$ & $48.18 \pm 41.22$ & $81.96 \pm 54.49$ & 0.0000 \\
\hline Coenzyme transport and metabolism & $\mathrm{H}$ & $40.25 \pm 17.78$ & $82.91 \pm 47.76$ & $69.26 \pm 45.21$ & $109.84 \pm 39.55$ & 0.0000 \\
\hline Inorganic ion transport and metabolism & $P$ & $22.48 \pm 7.80$ & $89.40 \pm 61.77$ & $67.98 \pm 59.89$ & $127.67 \pm 60.67$ & 0.0000 \\
\hline $\begin{array}{l}\text { Secondary metabolites biosynthesis, transport } \\
\text { and catabolism }\end{array}$ & Q & $6.18 \pm 6.09$ & $32.34 \pm 40.30$ & $23.97 \pm 35.52$ & $50.04 \pm 44.50$ & 0.0000 \\
\hline Energy production and conversion & C & $48.63 \pm 16.77$ & $111.98 \pm 75.61$ & $91.70 \pm 69.58$ & $|48.99 \pm 82.3|$ & 0.0000 \\
\hline General function prediction only & $\mathrm{R}$ & $53.58 \pm 27.82$ & $187.75 \pm 106.15$ & $144.82 \pm 108.75$ & $265.65 \pm 119.15$ & 0.0000 \\
\hline Function unknown & $S$ & $43.23 \pm 27.19$ & $184.84 \pm 124.19$ & $139.52 \pm 122.80$ & $262.59 \pm 118.90$ & 0.0000 \\
\hline Total & & 669.43 & 1867.85 & 1484.35 & 2427.53 & \\
\hline
\end{tabular}

(b) Percent of genes in the different functional categories (\%)

\begin{tabular}{lllll}
\hline & & & & 19.15 \\
Information storage and processing $(\mathrm{B}+\mathrm{L}+\mathrm{K}+\mathrm{A}+\mathrm{J})$ & 29.60 & 22.07 & 23.16 & 20.61 \\
Cellular processes and signalling & 20.98 & 20.81 & 20.83 & 38.48 \\
$\begin{array}{l}(\mathrm{O}+\mathrm{U}+\mathrm{T}+\mathrm{D}+\mathrm{V}+\mathrm{M}+\mathrm{N}+\mathrm{Z}) \\
\text { Metabolism }(\mathrm{F}+\mathrm{E}+\mathrm{G}+\mathrm{I}+\mathrm{H}+\mathrm{P}+\mathrm{Q}+\mathrm{C})\end{array}$ & 34.97 & 37.17 & 36.85 & 21.76 \\
Poorly characterized $(\mathrm{R}+\mathrm{S})$ & 14.46 & 19.95 & 19.16 & \\
\hline
\end{tabular}

OI corresponds to obligate intracellular, FHA corresponds to facultative host-associated, HD corresponds to all host-dependent, FL corresponds to free-living bacteria.

$*_{p}$-values $<0.05$ are shown in bold to indicate significant differences between HD and FL bacteria (paired Student's $t$-test and Wilcoxon signed rank test)

COG category decreased in each step of specialization to an intracellular lifestyle (Figure 4). However, we suspected that gene loss was not random and resulted from a converging evolutionary process. To test this hypothesis, we developed a new statistical approach (Details in methods). We considered the most parsimonious hypothesis, suggesting that consistent gene presence in the free-living bacteria in a phylum indicates that the corresponding gene was probably present in the ancestor of that phylum, whereas the occasional absence of a gene in obligate intracellular bacteria might result from gene loss. Also, we con- sidered the repetition of gene loss across distantly related intracellular species in comparison with their close relative free-living bacteria indicative of convergent evolution. By comparing obligate intracellular to their phylogenetically close free-living relatives, in the same phylum, we identified a set of 100 COGs lost in concert by obligate intracellular bacteria from all phyla (Additional files 3 and 4, Table 4). The number of COGs lost in concert was significantly more important than expected (mean loss ratio \pm s.e.m $\left.=0.062 \pm 7.8 \times 10^{-3} \%\right)$ if the loss were random (Randomization test, $\mathrm{n}=2000, p<10^{-6}$ ) (Additional 
Table 2: Set of 100 essential COGs conserved in $99 \%$ of bacteria

\begin{tabular}{|c|c|c|}
\hline COG & Code & COG's description \\
\hline COG0563 & $\mathrm{F}$ & Adenylate kinase and related kinases \\
\hline COG0528 & $\mathrm{F}$ & Uridylate kinase \\
\hline COG0587 & L & DNA polymerase III, alpha subunit \\
\hline COG 2812 & $\mathrm{~L}$ & DNA polymerase III, gamma/tau subunits \\
\hline COG0592 & $\mathrm{L}$ & DNA polymerase sliding clamp subunit (PCNA homolog) \\
\hline COG0358 & $\mathrm{L}$ & DNA primase (bacterial type) \\
\hline COG0084 & $\mathrm{L}$ & Mg-dependent DNase \\
\hline COG0305 & $\mathrm{L}$ & Replicative DNA helicase \\
\hline COG0629 & $\mathrm{L}$ & Single-stranded DNA-binding protein \\
\hline COG0I88 & $\mathrm{L}$ & Type IIA topoisomerase (DNA gyrase/topo II, topoisomerase IV), A subunit \\
\hline COG0I87 & $\mathrm{L}$ & Type IIA topoisomerase (DNA gyrase/topo II, topoisomerase IV), B subunit \\
\hline COG0202 & $\mathrm{K}$ & DNA-directed RNA polymerase, alpha subunit/40 kD subunit \\
\hline COG0086 & $\mathrm{K}$ & DNA-directed RNA polymerase, beta' subunit/160 kD subunit \\
\hline COG0568 & $\mathrm{K}$ & DNA-directed RNA polymerase, sigma subunit (sigma70/sigma32) \\
\hline COG057I & $\mathrm{K}$ & dsRNA-specific ribonuclease \\
\hline COG0250 & $\mathrm{K}$ & Transcription antiterminator \\
\hline COG0I95 & $\mathrm{K}$ & Transcription elongation factor \\
\hline COG008I & J & Ribosomal protein LI \\
\hline COG0244 & j & Ribosomal protein LIO \\
\hline COG0080 & j & Ribosomal protein LII \\
\hline COG0I02 & j & Ribosomal protein LI3 \\
\hline COG0093 & j & Ribosomal protein LI4 \\
\hline COG0200 & j & Ribosomal protein LI5 \\
\hline COG0197 & j & Ribosomal protein LI6/LIOE \\
\hline COG0203 & j & Ribosomal protein LI7 \\
\hline COG0256 & $j$ & Ribosomal protein LI8 \\
\hline COG0335 & j & Ribosomal protein LI9 \\
\hline COG0090 & j & Ribosomal protein L2 \\
\hline COG0292 & $\mathrm{j}$ & Ribosomal protein L20 \\
\hline COG009I & j & Ribosomal protein L22 \\
\hline COG0089 & $j$ & Ribosomal protein L23 \\
\hline COG0I98 & j & Ribosomal protein L24 \\
\hline COG02II & $j$ & Ribosomal protein L27 \\
\hline COG0087 & j & Ribosomal protein L3 \\
\hline COG0254 & j & Ribosomal protein L3I \\
\hline COG0088 & $j$ & Ribosomal protein L4 \\
\hline COG0094 & $j$ & Ribosomal protein L5 \\
\hline COG0097 & j & Ribosomal protein L6P/L9E \\
\hline COG0222 & j & Ribosomal protein L7/LI2 \\
\hline COG005I & $\mathrm{j}$ & Ribosomal protein SIO \\
\hline COG0I00 & j & Ribosomal protein SII \\
\hline COG0048 & $j$ & Ribosomal protein $\mathrm{SI} 2$ \\
\hline COG0099 & j & Ribosomal protein $\mathrm{SI} 3$ \\
\hline COG0I84 & $j$ & Ribosomal protein SI5P/SI3E \\
\hline COG0228 & j & Ribosomal protein SI6 \\
\hline COG0I86 & j & Ribosomal protein SI7 \\
\hline COG0238 & j & Ribosomal protein SI 8 \\
\hline COG0052 & j & Ribosomal protein S2 \\
\hline COG0268 & j & Ribosomal protein S20 \\
\hline COG0092 & $j$ & Ribosomal protein $\mathrm{S} 3$ \\
\hline COG0522 & $\mathrm{j}$ & Ribosomal protein S4 and related proteins \\
\hline COG0098 & j & Ribosomal protein S5 \\
\hline COG0360 & $j$ & Ribosomal protein S6 \\
\hline COG0049 & j & Ribosomal protein S7 \\
\hline COG0096 & j & Ribosomal protein $\mathbf{S 8}$ \\
\hline COG0I03 & j & Ribosomal protein 59 \\
\hline COG0233 & j & Ribosome recycling factor \\
\hline COG0858 & $j$ & Ribosome-binding factor $\mathrm{A}$ \\
\hline COG00I3 & $j$ & Alanyl-tRNA synthetase \\
\hline
\end{tabular}


Table 2: Set of 100 essential COGs conserved in $99 \%$ of bacteria (Continued)

\begin{tabular}{|c|c|c|}
\hline COG0018 & J & Arginyl-tRNA synthetase \\
\hline COG02I5 & $\mathrm{J}$ & Cysteinyl-tRNA synthetase \\
\hline COG0008 & J & Glutamyl- and glutaminyl-tRNA synthetases \\
\hline COG0I24 & $\mathrm{J}$ & Histidyl-tRNA synthetase \\
\hline COG0060 & $\mathrm{J}$ & Isoleucyl-tRNA synthetase \\
\hline COG0495 & $\mathrm{J}$ & Leucyl-tRNA synthetase \\
\hline COG0I43 & $\mathrm{J}$ & Methionyl-tRNA synthetase \\
\hline COG00I6 & J & Phenylalanyl-tRNA synthetase alpha subunit \\
\hline COG0072 & $\mathrm{J}$ & Phenylalanyl-tRNA synthetase beta subunit \\
\hline COG0193 & $\mathrm{J}$ & Peptidyl-tRNA hydrolase \\
\hline COG0442 & $\mathrm{J}$ & Prolyl-tRNA synthetase \\
\hline COG0I72 & $\mathrm{J}$ & Seryl-tRNA synthetase \\
\hline COG044I & $\mathrm{J}$ & Threonyl-tRNA synthetase \\
\hline COG0I80 & $\mathrm{J}$ & Tryptophanyl-tRNA synthetase \\
\hline COG0I62 & $\mathrm{J}$ & Tyrosyl-tRNA synthetase \\
\hline COG0024 & $\mathrm{J}$ & Methionine aminopeptidase \\
\hline COG0336 & J & tRNA-(guanine-NI)-methyltransferase \\
\hline COG0030 & $\mathrm{J}$ & Dimethyladenosine transferase (rRNA methylation) \\
\hline COG0012 & $\mathrm{J}$ & Predicted GTPase, probable translation factor \\
\hline COG02I6 & $\mathrm{J}$ & Protein chain release factor $A$ \\
\hline COG0050 & $\mathrm{J}$ & GTPases - translation elongation factors \\
\hline COG023I & $\mathrm{J}$ & Translation elongation factor $\mathrm{P}$ (EF-P)/translation initiation factor $5 \mathrm{~A}$ (elF-5A) \\
\hline COG0264 & $\mathrm{J}$ & Translation elongation factor Ts \\
\hline COG0480 & $\mathrm{J}$ & Translation elongation factors (GTPases) \\
\hline COG036I & $\mathrm{J}$ & Translation initiation factor I (IF-I) \\
\hline COG0532 & $\mathrm{J}$ & Translation initiation factor 2 (IF-2; GTPase) \\
\hline COG0290 & $\mathrm{J}$ & Translation initiation factor 3 (IF-3) \\
\hline COG0465 & $\mathrm{O}$ & ATP-dependent Zn proteases \\
\hline COG0484 & O & DnaJ-class molecular chaperone with C-terminal Zn finger domain \\
\hline COG0533 & O & Metal-dependent proteases with possible chaperone activity \\
\hline COG0443 & O & Molecular chaperone \\
\hline COG0576 & O & Molecular chaperone GrpE (heat shock protein) \\
\hline COG069I & $\mathrm{O}$ & tmRNA-binding protein \\
\hline COG0653 & U & Preprotein translocase subunit SecA (ATPase, RNA helicase) \\
\hline COG0201 & $\cup$ & Preprotein translocase subunit SecY \\
\hline COG0706 & $\mathrm{U}$ & Preprotein translocase subunit YidC \\
\hline COG048I & M & Membrane GTPase LepA \\
\hline COG0275 & M & Predicted S-adenosylmethionine-dependent methyltransferase involved in cell envelope biogenesis \\
\hline COG0536 & $\mathrm{R}$ & Predicted GTPase \\
\hline COGII60 & $\mathrm{R}$ & Predicted GTPases \\
\hline COG0319 & $\mathrm{R}$ & Predicted metal-dependent hydrolase \\
\hline
\end{tabular}

file 5). The set of 100 COGs lost in concert among the obligate intracellular bacteria, mainly encoded metabolism (41\%) and cellular process (35\%) proteins (Table 3), showing that gene loss is function-dependent (Chisquared test for independence $\chi^{2}=36.4$, degrees of freedom $d f=3, p<10^{-6}$ ). The obligate intracellular bacteria from different phyla did not lose COGs independently (Binomial distribution, $p<10^{-6}$ ) (Additional file 6). Thereby, using statistical tests, we demonstrated that there is a causal link between specialization and gene loss. The common loss of the same genes in obligate intracellular bacteria from different phyla reflects the convergent evolution of these specialized bacteria in relation to their lifestyle (Figure 1).

\section{Correlation between transcription, translation and growth} rate

The DNA encoding ribosomal RNAs (rRNA) genes of bacteria are typically organized in operons with the general structure 16S-23S-5S, transfer RNA (tRNA) genes are often found in the spacer between the 16S and the 23S rRNA genes [38]. Host-dependent bacteria have fewer copies of each rRNA gene than free-living and significantly lower copy number of typical rRNA operon $(2.52 \pm 2.53 \mathrm{vs}$. 4.91 \pm 2.98 copies, $p<10^{-6}$ ). This difference in the number of typical rRNA operons between host-dependent and freeliving bacteria remained significant when adjusted for genome size $(1.07 \pm 1.06$ vs. $1.46 \pm 0.97$ operons $/ \mathrm{Mb}, p=$ $0.001)$. Atypical operons, where the general structure 16S23S-5S is disrupted by protein-coding genes, were found significantly more frequently in host-dependent than in free-living bacteria (38 vs. 5, Chi-squared test for inde- 
Table 3: Functional classification of 100 conserved and 100 lost COGs

\begin{tabular}{|c|c|c|c|}
\hline COG description & Code & Conserved & Lost \\
\hline Chromatine structure and dynamics & B & 0 & 0 \\
\hline Replication, recombination and repair & $\mathbf{L}$ & 9 & I \\
\hline Transcription & $\mathbf{K}$ & 6 & $5^{*}$ \\
\hline Rna processing and modification & $\mathbf{A}$ & 0 & 0 \\
\hline Translation, ribosomal structure and biogenesis & J & 69 & 3 \\
\hline Information storage and processing & & 84 & 9 \\
\hline Posttranslational modification, protein turnover, chaperones & $\mathbf{0}$ & 6 & $11 *$ \\
\hline Intracellular trafficking, secretion, and vesicular transport & $\mathbf{u}$ & 3 & 0 \\
\hline Signal transduction mechanisms & $\mathbf{T}$ & 0 & $12 *$ \\
\hline Cell cycle control, cell division, chromosome partitioning & D & 0 & 1 \\
\hline Defense mechanisms & $\mathbf{v}$ & 0 & 0 \\
\hline Cell wall/membrane/envelope biogenesis & $M$ & 2 & 6 \\
\hline Cell motility & $\mathbf{N}$ & 0 & $8^{*}$ \\
\hline Cellular processes and signaling & & II & 38 \\
\hline Nucleotide transport and metabolism & $\mathbf{F}$ & 2 & 0 \\
\hline Amino acid transport and metabolism & $\mathbf{E}$ & 0 & $17^{*}$ \\
\hline Carbohydrate transport and metabolism & G & 0 & I* \\
\hline Lipid transport and metabolism & $\mathbf{I}$ & 0 & $2^{*}$ \\
\hline Coenzyme transport and metabolism & $\mathbf{H}$ & 0 & 7 \\
\hline Inorganic ion transport and metabolism & $\mathbf{P}$ & 0 & 8 \\
\hline Secondary metabolites biosynthesis, transport and catabolism & $\mathbf{Q}$ & 0 & $3^{*}$ \\
\hline Energy production and conversion & C & 0 & 8 \\
\hline Metabolism & & 2 & 46 \\
\hline General function prediction only & $\mathbf{R}$ & 3 & 10 \\
\hline Function unknown & $\mathbf{S}$ & 0 & 7 \\
\hline Poorly characterized & & 3 & 17 \\
\hline
\end{tabular}

*Some of the COGs in the corresponding functional category belong to other categories as well.

pendence $\chi^{2}=49.9, d f=1, p<10^{-6}$, these bacteria are listed in Additional file 1). Our data show that different independent clades of host-dependent bacteria contain few copies of ribosomal RNA genes which do not form an operon (Figure 1). The split in rRNA operon is a key evolutionary factor for obligate intracellular bacteria from the order Rickettsiales [39,40]. It has been suggested that recombination between gene repeats might have led to both gene loss and genome shuffling in Rickettsia and Wolbachia spp. [41,42]. The split in rRNA operon helps to elucidate one of the mechanisms of specialized intracellular genomes evolution.

When counting the number of genes involved in transcription, host-dependent bacteria were found to have significantly fewer transcriptional regulators. This decrease is pronounced in obligate intracellular bacteria (6.98 \pm 12.32 genes/Mb) compared to facultative host-associated $\left(19.07 \pm 11.49\right.$ genes/Mb, $\left.p<10^{-6}\right)$ and to free-living bacteria $\left(28.69 \pm 11.18\right.$ genes/Mb, $\left.p<10^{-6}\right)$. The ratio of genes involved in transcriptional regulation over the total number of genes involved in transcription in free-living $(66.3 \pm 10.7 \%)$ is significantly greater than that of facultative host-associated $(52.46 \pm 17.5 \%)$ and than that of obligate intracellular bacteria (26.11 $\pm 14.8 \%)$ (unpaired Student's t-test, both $p<10^{-6}$ ). These genomic features dealing with transcription and translation (the rRNA apparatus) may have an implication in a phenotypic criterion such as growth time. When compared to free-living bacteria, obligate intracellular bacteria have lower copy numbers of the rRNA genes, increased rearranged rRNA operon structures, and fewer transcriptional regulators, and a tendency of slow growth (Figure 5). Moreover, we found a significant negative correlation between growth time on one side and the number of rRNA operons and transcriptional regulators per $\mathrm{Mb}$ on the other side $\left(F_{2,284}=93.7\right.$; adjusted $R^{2}=0.393 ; p<10^{-6}$, Additional file 1$)$. These findings are all correlated with the obligate intracellular bacterial lifestyle and make sense with respect to the physical constraints of that lifestyle. Free-living bacteria exhibit larger genomes, more lateral gene transfer [13], and more rRNA operons. They have great capabilities to adapt to different environmental surroundings, like soil and water. A high copy number of rRNA may be necessary to tolerate increased gene content and larger genome size. The occurrence of multiple typical operons may be important in the ability of bacteria to respond to changing growth conditions [43]. Moreover, the versatile environments of free-living organisms require greater regulatory potential than do the relatively stable niches of obligate intracellular bacteria [4,44]. Specialization is correlated with a lower possibility of gene 


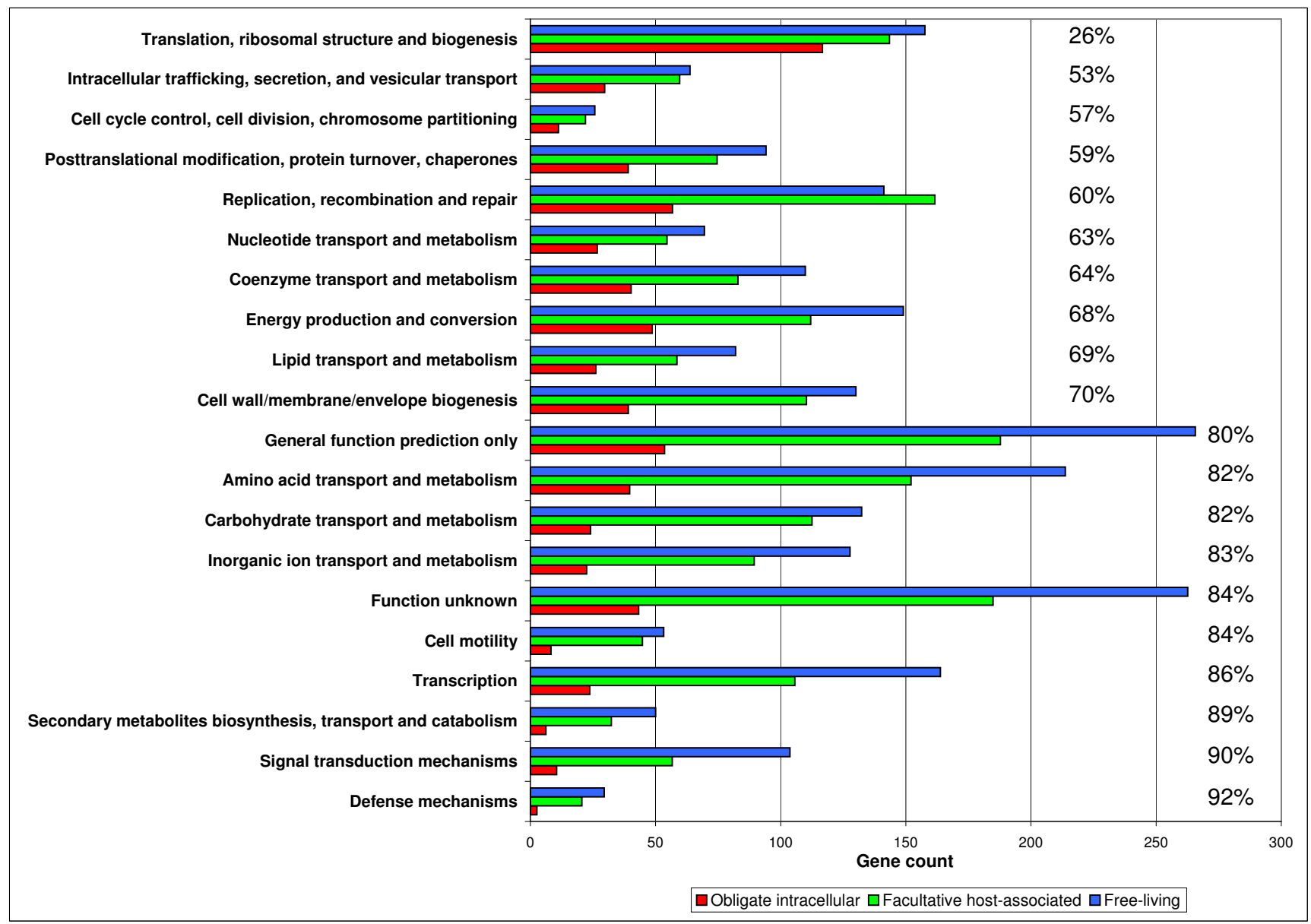

\section{Figure 4}

Functions lost during specialization. The bars represent the mean number of loci in different functional categories based on functional categorizations established for the clusters of Orthologous Groups (COGs).The proportion of genes lost by obligate intracellular compared to free-living bacteria is indicated next to the bars.

exchanges with other bacteria [13] add to this a more constant environment that may explain the lack of positive selection for both rRNA operon copies and transcriptional regulators [24]. Finally, the decrease of host-dependent bacteria's growth rate may be critical to synchronize with that of their host cells in order to avoid detrimental virulence (cell lysis).

\section{Divergence of parasites and mutualists}

Among obligate intracellular bacteria, we observed differences between the genomic repertoires of mutualists and parasites that seem to reflect the nature of the relationship these organisms have with their host-cells (beneficial and harmful, respectively). Mutualists have smaller genomes than parasites $(0.72 \pm 0.27$ vs. $1.39 \pm 0.49 \mathrm{Mb}$, Wilcoxon rank sum test, $p<10^{-6}$ ) and they have significantly less genes in almost all COGs categories. Nevertheless, the genome content difference between mutualists and parasites is not significant for genes involved in amino acid transport and metabolism $(40.62 \pm 21.21$ vs. $39.19 \pm$ 20.38), nucleotide transport and metabolism (25.38 \pm 11.30 vs. $27.33 \pm 10.20)$, cell motility $(8.85 \pm 12.66$ vs. $7.93 \pm 9.59)$, and cell cycle control, cell division, and chromosome partition $(9.38 \pm 5.09$ vs. $12.07 \pm 5.59)$. These findings show that despite genome reduction, mutualists have retained genes involved in the transport and metabolism of amino acid and nucleotide, genes for cell motility and cell cycle control. Moreover, $8.76 \%$ of the genome vs. only $5.18 \%$ (paired Student's t-test, $p<10^{-}$ 4 ) is occupied by genes for amino acid transport and metabolism (Figure 6). Parasitic reduced genomes have eliminated genes underlying biosynthesis of amino acids that can be obtained from the host cytoplasm [45], whereas mutualistic genomes have retained genes for the biosynthesis of amino acids required by their hosts [46]. Likewise, mutualists devote a higher fraction of their genomes than parasites for genes involved in nucleotide transport and metabolism (4.7\% vs. $3.77 \%)$ and genes for 
Table 4: Set of 100 COGs lost by obligate intracellular bacteria

\begin{tabular}{|c|c|c|}
\hline COG & Code & COG's description \\
\hline COG2264 & J & Ribosomal protein LII methylase \\
\hline COGII88 & j & Ribosome-associated heat shock protein implicated in the recycling of the $50 \mathrm{~S}$ subunit (S4 paralog) \\
\hline COG2265 & j & SAM-dependent methyltransferases related to tRNA (uracil-5-)-methyltransferase \\
\hline COGI595* & $\mathrm{K}$ & DNA-directed RNA polymerase specialized sigma subunit, sigma24 homolog \\
\hline COGI508 & $\mathrm{K}$ & DNA-directed RNA polymerase specialized sigma subunit, sigma54 homolog \\
\hline COGI522 & K & Transcriptional regulators \\
\hline COGII67 & KE & $\begin{array}{l}\text { Transcriptional regulators containing a DNA-binding HTH domain and an aminotransferase domain (MocR family) and } \\
\text { their eukaryotic orthologs }\end{array}$ \\
\hline COGI974* & KT & SOS-response transcriptional repressors (RecA-mediated autopeptidases) \\
\hline COGI643 & $\mathrm{L}$ & HrpA-like helicases \\
\hline COG0277* & C & FAD/FMN-containing dehydrogenases \\
\hline COG0247* & C & Fe-S oxidoreductase \\
\hline COG2225* & C & Malate synthase \\
\hline COG 1902 & $\mathrm{C}$ & NADH:flavin oxidoreductases, Old Yellow Enzyme family \\
\hline COG0778* & C & Nitroreductase \\
\hline COG2352* & $\mathrm{C}$ & Phosphoenolpyruvate carboxylase \\
\hline COGI600 & C & Uncharacterized Fe-S protein \\
\hline COGI062* & C & Zn-dependent alcohol dehydrogenases, class III \\
\hline COG0239 & $\mathrm{D}$ & Integral membrane protein possibly involved in chromosome condensation \\
\hline COG0683 & $\mathrm{E}$ & ABC-type branched-chain amino acid transport systems, periplasmic component \\
\hline COGII76 & $\mathrm{E}$ & ABC-type spermidine/putrescine transport system, permease component I \\
\hline COGII77 & $\mathrm{E}$ & ABC-type spermidine/putrescine transport system, permease component II \\
\hline COG2049* & $E$ & Allophanate hydrolase subunit I \\
\hline COGI984* & $\mathrm{E}$ & Allophanate hydrolase subunit 2 \\
\hline COG2303* & $\mathrm{E}$ & Choline dehydrogenase and related flavoproteins \\
\hline COG00I4* & $\mathrm{E}$ & Gamma-glutamyl phosphate reductase \\
\hline COG0405 & $\mathrm{E}$ & Gamma-glutamyltransferase \\
\hline COG0263* & $\mathrm{E}$ & Glutamate 5-kinase \\
\hline COG0665 & $\mathrm{E}$ & Glycine/D-amino acid oxidases (deaminating) \\
\hline COG0346* & $\mathrm{E}$ & Lactoylglutathione lyase and related lyases \\
\hline COG2755* & $\mathrm{E}$ & Lysophospholipase LI and related esterases \\
\hline COGI4I0* & $\mathrm{E}$ & Methionine synthase I, cobalamin-binding domain \\
\hline COG0347 & $\mathrm{E}$ & Nitrogen regulatory protein PII \\
\hline COG 1280 & $E$ & Putative threonine efflux protein \\
\hline COG2008 & $\mathrm{E}$ & Threonine aldolase \\
\hline COGI762 & GT & Phosphotransferase system mannitol/fructose-specific IIA domain (Ntr-type) \\
\hline COG03I5 & $\mathrm{H}$ & Molybdenum cofactor biosynthesis enzyme \\
\hline COG2896 & $\mathrm{H}$ & Molybdenum cofactor biosynthesis enzyme \\
\hline COG0303* & $\mathrm{H}$ & Molybdopterin biosynthesis enzyme \\
\hline COG052I* & $\mathrm{H}$ & Molybdopterin biosynthesis enzymes \\
\hline COG03I4 & $\mathrm{H}$ & Molybdopterin converting factor, large subunit \\
\hline COGI977 & $\mathrm{H}$ & Molybdopterin converting factor, small subunit \\
\hline COG0746 & $\mathrm{H}$ & Molybdopterin-guanine dinucleotide biosynthesis protein A \\
\hline COG2267* & I & Lysophospholipase \\
\hline COG0318 & IQ & Acyl-CoA synthetases (AMP-forming)/AMP-acid ligases II \\
\hline COG2230* & $M$ & Cyclopropane fatty acid synthase and related methyltransferases \\
\hline COG 1596 & M & Periplasmic protein involved in polysaccharide export \\
\hline COG0810 & M & Periplasmic protein TonB, links inner and outer membranes \\
\hline COG 1247 & M & Sortase and related acyltransferases \\
\hline COG2I48 & M & Sugar transferases involved in lipopolysaccharide synthesis \\
\hline COG3206 & M & Uncharacterized protein involved in exopolysaccharide biosynthesis \\
\hline COGI580 & $\mathrm{N}$ & Flagellar basal body-associated protein \\
\hline COGI29I & $\mathrm{N}$ & Flagellar motor component \\
\hline COG 1344 & $\mathrm{~N}$ & Flagellin and related hook-associated proteins \\
\hline COG0643 & NT & Chemotaxis protein histidine kinase and related kinases \\
\hline COG220I & NT & Chemotaxis response regulator containing a CheY-like receiver domain and a methylesterase domain \\
\hline COG0835 & NT & Chemotaxis signal transduction protein \\
\hline COG0840 & NT & Methyl-accepting chemotaxis protein \\
\hline COG 1352 & NT & Methylase of chemotaxis methyl-accepting proteins \\
\hline
\end{tabular}


Table 4: Set of 100 COGs lost by obligate intracellular bacteria (Continued)

\begin{tabular}{|c|c|c|}
\hline COG0229 & $\mathrm{O}$ & Conserved domain frequently associated with peptide methionine sulfoxide reductase \\
\hline COG4235 & $\mathrm{O}$ & Cytochrome c biogenesis factor \\
\hline COGI28I & O & Disulfide bond chaperones of the HSP33 family \\
\hline COG0386 & $\mathrm{O}$ & Glutathione peroxidase \\
\hline COG 2360 & O & Leu/Phe-tRNA-protein transferase \\
\hline COG0652* & 0 & Peptidyl-prolyl cis-trans isomerase (rotamase) - cyclophilin family \\
\hline COGI764 & O & Predicted redox protein, regulator of disulfide bond formation \\
\hline COG25I8 & O & Protein-L-isoaspartate carboxylmethyltransferase \\
\hline COG3II8* & O & Thioredoxin domain-containing protein \\
\hline COG2844 & O & UTP:GInB (protein PII) uridylyltransferase \\
\hline COGI39|* & OT & Glutamine synthetase adenylyltransferase \\
\hline COG0725 & $P$ & ABC-type molybdate transport system, periplasmic component \\
\hline COG0600 & $P$ & ABC-type nitrate/sulfonate/bicarbonate transport system, permease component \\
\hline COG0004 & $P$ & Ammonia permease \\
\hline COGI393* & $P$ & Arsenate reductase and related proteins, glutaredoxin family \\
\hline COG0704* & $P$ & Phosphate uptake regulator \\
\hline COG0855* & $P$ & Polyphosphate kinase \\
\hline COG $2897 *$ & $P$ & Rhodanese-related sulfurtransferase \\
\hline COG0659* & $P$ & Sulfate permease and related transporters (MFS superfamily) \\
\hline COG0I79* & $\mathrm{Q}$ & 2-keto-4-pentenoate hydratase/2-oxohepta-3-ene-1,7-dioic acid hydratase (catechol pathway) \\
\hline COG3I27 & $\mathrm{Q}$ & Predicted ABC-type transport system involved in lysophospholipase LI biosynthesis, permease component \\
\hline COG0664* & $\mathrm{T}$ & cAMP-binding proteins - catabolite gene activator and regulatory subunit of cAMP-dependent protein kinases \\
\hline COG500I* & $\mathrm{T}$ & Predicted signal transduction protein containing a membrane domain, an EAL and a GGDEF domain \\
\hline COG0394 & $\mathrm{T}$ & Protein-tyrosine-phosphatase \\
\hline COG3852 & $\mathrm{T}$ & Signal transduction histidine kinase, nitrogen specific \\
\hline COG 1253 & $\mathrm{R}$ & Hemolysins and related proteins containing CBS domains \\
\hline COG0714* & $\mathrm{R}$ & MoxR-like ATPases \\
\hline COGI74I & $\mathrm{R}$ & Pirin-related protein \\
\hline COG0388* & $\mathrm{R}$ & Predicted amidohydrolase \\
\hline COG208I & $\mathrm{R}$ & Predicted flavoproteins \\
\hline COG 1694 & $\mathrm{R}$ & Predicted pyrophosphatase \\
\hline COGI6II* & $\mathrm{R}$ & Predicted Rossmann fold nucleotide-binding protein \\
\hline COG0523 & $\mathrm{R}$ & Putative GTPases (G3E family) \\
\hline COG2334 & $\mathrm{R}$ & Putative homoserine kinase type II (protein kinase fold) \\
\hline COGI540* & $\mathrm{R}$ & Uncharacterized proteins, homologs of lactam utilization protein B \\
\hline COG0397 & S & Uncharacterized conserved protein \\
\hline COGI576 & S & Uncharacterized conserved protein \\
\hline $\operatorname{COG} 2127^{*}$ & $S$ & Uncharacterized conserved protein \\
\hline COG2606* & S & Uncharacterized conserved protein \\
\hline COG2983 & S & Uncharacterized conserved protein \\
\hline COGI67I & $S$ & Uncharacterized protein conserved in bacteria \\
\hline COG3024 & S & Uncharacterized protein conserved in bacteria \\
\hline
\end{tabular}

*indicates COGs that are present in the genome of Mycobacterium leprae

translation, ribosomal structure and biogenesis (22.92 vs. $16.74 \%$ ) (paired Student's t-test, all $p<0.05$ ). In contrast, mutualists devote a lower fraction of their genomes than parasites for genes involved in lipid transport and metabolism (2.98 vs. $4.13 \%)$, secondary metabolites biosynthesis transport and metabolism $(0.62$ vs. $0.95 \%)$, in cell wall, membrane and envelope (4.76 vs. $5.80 \%$ ) signal transduction mechanisms ( 0.61 vs. $1.78 \%$ ) and intracellular trafficking and signaling (3.47 vs. $4.84 \%$ ) (paired Student's t-test, all $p<0.05$ ) (Figure 6). Some genes increased their representation per genome size in the smaller genomes of mutualists compared to parasitic genomes, such as genes encoding for proteins involved in translation $(169.54 \pm 56.24$ vs. $92.64 \pm 18.99$ genes $/ \mathrm{Mb})$; post-translational modification, protein turnover, and chaperones $(47.13 \pm 15.57$ vs. $32.22 \pm 6.98$ genes $/ \mathrm{Mb})$; cell motility $(14.11 \pm 19.26$ vs. $6.43 \pm 8.49$ genes/Mb); energy production and conversion $(55.26 \pm 19.04$ vs. $40.38 \pm 10.50$ genes/Mb); and the transport and metabolism of nucleotides ( $34.70 \pm 12.67$ vs. $20.21 \pm 6.89$ genes/ $\mathrm{Mb})$, amino acids (69.56 \pm 46.10 vs. $27.91 \pm 7.64$ genes/ $\mathrm{Mb})$, carbohydrates $(31.07 \pm 13.32$ vs. $19.09 \pm 7.78$ genes/ $\mathrm{Mb})$, and coenzymes $(43.10 \pm 28.66$ vs. $33.17 \pm 9.73$ genes $/ \mathrm{Mb}$, paired Student's t-test, all $p<0.05)$. In contrast, parasites have significantly more genes/Mb involved in signal transduction mechanisms $(10.02 \pm 5.25$ vs. $4.68 \pm$ 2.35, paired Student's t-test, $p=0.011$ ) that may facilitate the process of entry and survival in cells; as parasitic life 


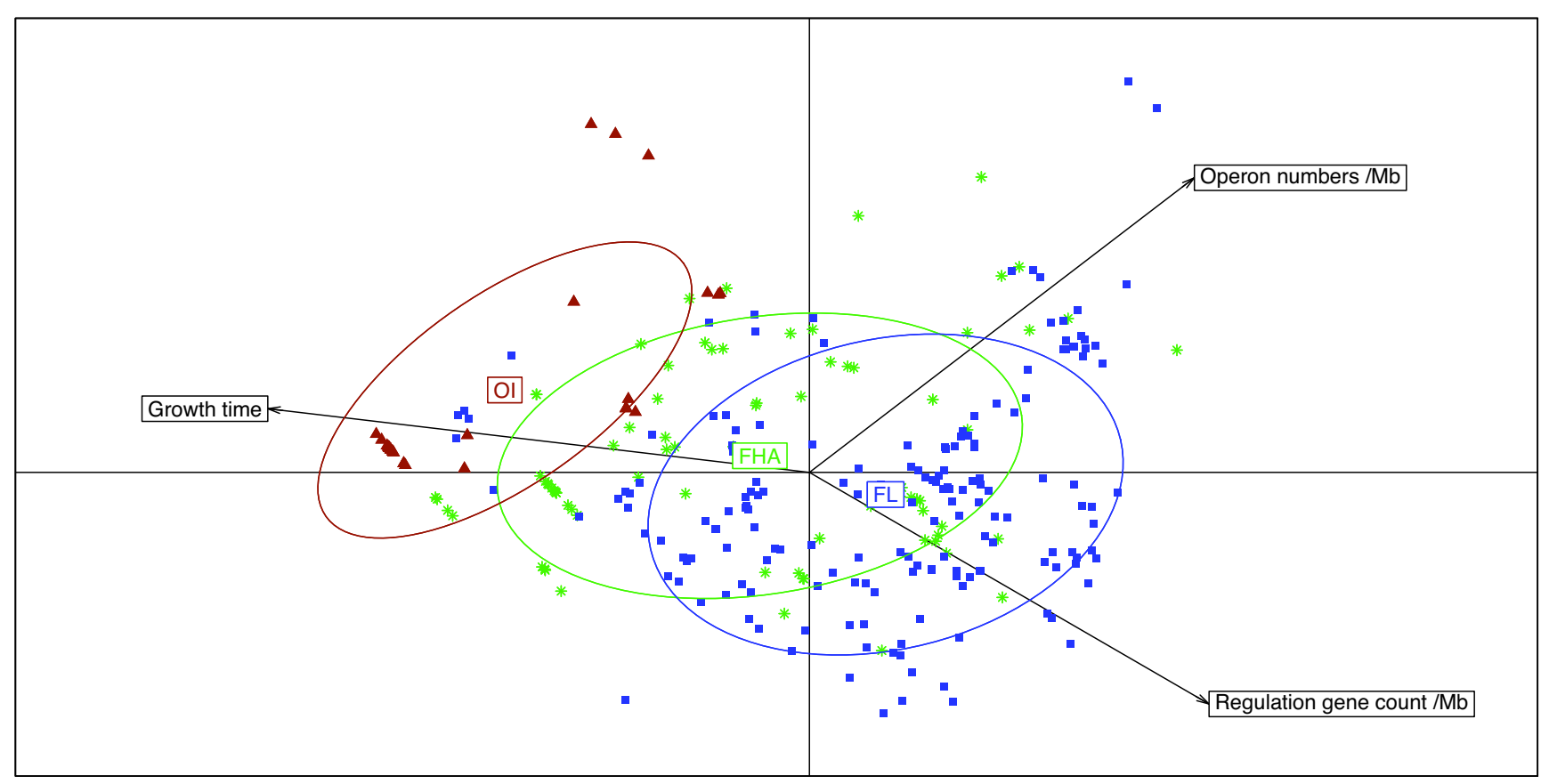

\section{Figure 5}

Relationship between growth time, operon number and transcriptional regulators per Mb. Bacteria were classified into 3 categories depending on the experimental growth time: fast growing (24-48 hours), median ( 3 to 7 days) and slow growing fastidious bacteria (more than 7 days). The 284 genomes for which information about time of growth is available are projected on the first two Principal Component Analysis (PCA) axes, which represent $66.2 \%$ and $19.5 \%$ of the total inertia. OI, obligate intracellular bacteria, dark red triangles; FHA, facultative host-associated, green asterisks; FL, free-living, blue squares.

requires passage outside the host cell to allow horizontal transmission [47]. Parasites exhibit a very specialized repertoire of secretory pathway genes, type II, IV, and VI (Wilcoxon rank sum test, $p<0.05$, Additional file 7 ), enabling them to modulate the host environment by secreted effector molecules [48]. This divergence between parasites' and mutualists' genomes is striking because intracellular parasites have been previously considered as a possible intermediate step to a mutualist lifestyle, en route to the extreme situation of becoming organelles (mitochondria and chloroplasts). Our comparative genomics of parasites and mutualists point out to general similarities and distinctions in the evolution of bacteria specialized to intracellular lifestyle. Obligate intracellular genomes have undergone a reductive evolution, however they have evolved different strategies for bacteria-host interactions and they have lost and conserved genes accordingly [49]. Finally, transitions between parasitism and mutualism might be restricted, owing to the irreversible loss of genes and the associated functional capabilities.

\section{Conclusion}

Based on the comparative genomics of a large number of bacterial genomes, we postulate that bacterial specialization is a one-way irreversible and converging journey causing massive gene loss. New specialists are constantly provided by free-living bacterial community reservoir. In contrast to what was initially hypothesized, the evolution of pathogenic bacteria, that are specialized bacteria of particular interest to humans [50], consists mainly of gene losses $[10,51,52]$. This general evolution strategy was recently confirmed for Rickettsia species (unpublished data), Mycobacterium tuberculosis $[53,54]$ and Mycobacterium ulcerans [55]; free-living bacteria having more genes named virulence factors than do pathogenic bacteria [13]. It is noteworthy that virulence factors, like genes encoding for the ATP/ADP translocases have been identified in Chlamydiae and Rickettsiae [56,57]. The presence of these transport systems in obligate intracellular parasites' genomes helps to exploit the host's ATP [9]. It has been suggested that these transport systems have been transferred horizontally to obligate intracellular bacteria during their specialization to an intracellular parasitic lifestyle [58]. Lateral gene transfer seems to be a very rare event in the evolution of intracellular bacteria, comparing to the gene loss events [13]. Increase in virulence may, therefore, be related to the loss of regulation rather than to gene acquisition [52]. 


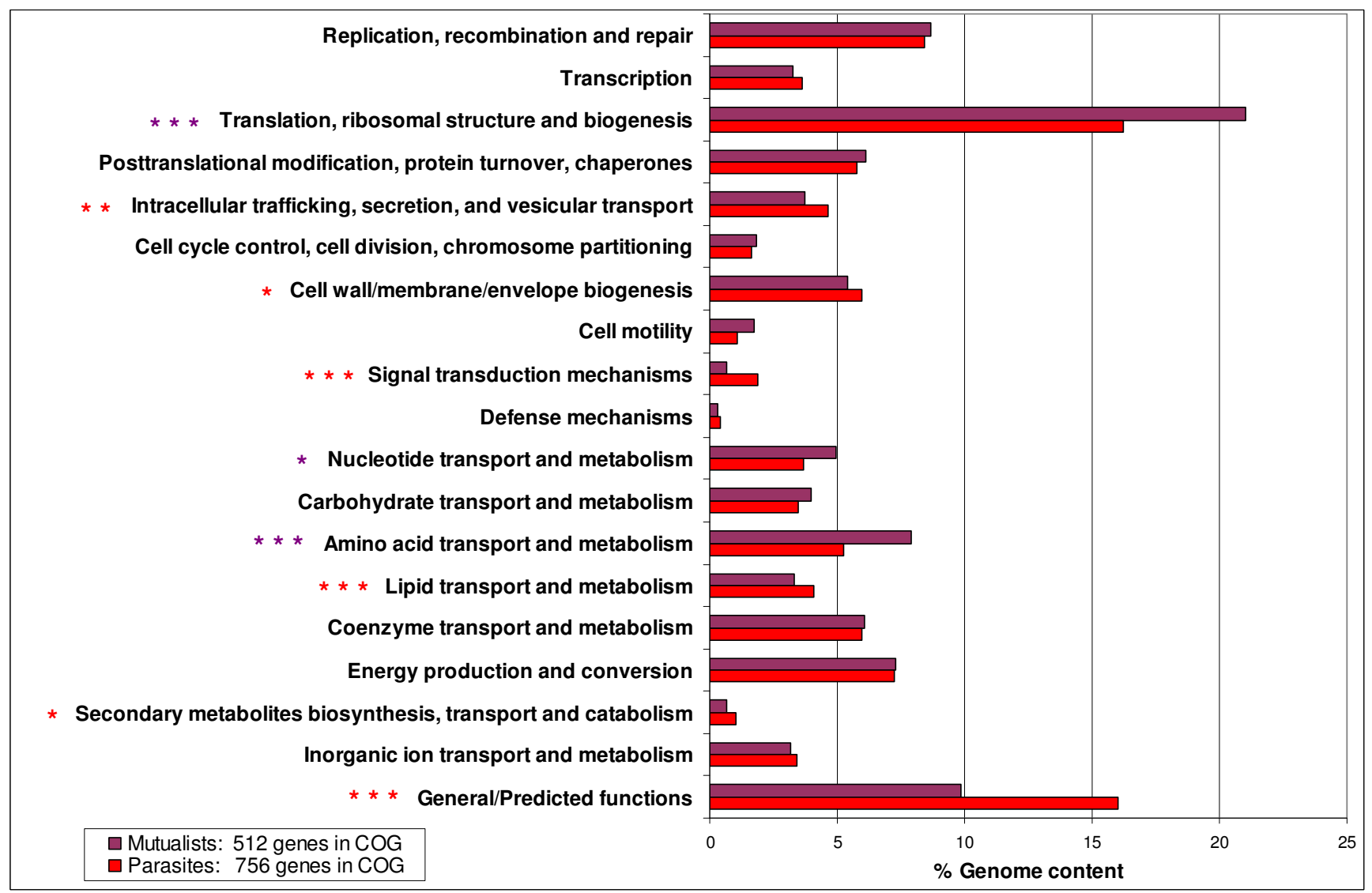

Figure 6

Comparison of the genome content from mutualistic and parasitic bacteria. Bars correspond to the mean number of genes in a given COG divided by the total number of genes. The significance of results in the figure is represented by triple asterisks $(* * *)$ indicating $p \leq 0.00 \mathrm{I}$, double asterisks $(* *)$ indicating $p \leq 0.0 \mathrm{I}$ and a single asterisk $(*)$ indicating $p \leq 0.05$ (paired Student's t-test).

\section{Methods}

\section{Genome data}

A total of 317 bacterial genomes were obtained from the NCBI website $\mathrm{ftp}$ //ftp.ncbi.nih.gov/genbank/genomes/ Bacteria/ together with their genome size, GC content, and the number of genes. We classified bacterial species on the basis of their ecological diversity: host-dependent bacteria living in association with eukaryotic cells and free-living bacteria living in soil, water, or in the air, independently of a eukaryotic cell according to the information given in literature. Host-dependent bacteria were divided into two subgroups: facultative host-associated and obligate intracellular. Obligate intracellular bacteria were classified as mutualists or parasites, depending on the effect of the association on the fitness of the host: positive or negative, respectively (The entire list of studied bacteria along with their genome features can be found in Additional file 1). In this paper, the term "specialists" refers to obligate intracellular bacteria specialized to an intracellular lifestyle.

\section{Identification of orthologs}

We retrieved protein sequence data for bacterial genomes from the KEGG database [59] ftp://ftp.genome.jp/pub/ kegg/genes/fasta/ and COG data from NCBI $[60,61]$ http:/ /www.ncbi.nlm.nih.gov/COG/index.html. In the COG database, individual COGs are clustered into 23 functional categories, which are further grouped into four major classes: information storage and processing, cellular processes and signaling, metabolism and poorly characterized. Each set of all predicted proteins was compared to the COG profile database using the Reverse PSI-Blast program [25]. A significance score was determined for each COG so that any sequence not used to build the COG profile scored below this score. ORFs were assigned to a functional category according to the category where their best COG homolog is classified.

In the COG database constructed herein, the presence or absence of a COG in a given organism was noted as 1 or 0 , respectively [62]. On the basis of this matrix $[0,1]$ we 
performed a principal coordinate (PCO) analysis to suggest relationships between genomes [63]. For that we used the resulting pattern of 1 's and 0 's for the presence or absence of a COG to construct the matrix for Euclidean distances between pairs of points. Then we performed a projection to get a 2-dimensional visualization.

We determined the mean number of genes assigned to each COGs for each bacterial lifestyle. We compared the mean number of genes assigned to each COG function between free-living bacteria (125 organisms) and all hostdependent bacteria (125 organisms), then between freeliving and obligate intracellular bacteria (40 organisms), and between mutualists (13 organisms) and parasites (27 organisms). All data were analyzed with the R statistical software package http://cran.r-project.org/[64] using the Student's $t$-test (either paired or unpaired) for sample sizes of 30 or more per group and Wilcoxon signed rank test or Wilcoxon rank sum test for small samples (paired or independent samples, respectively). All tests were twotailed, and $p$-values $<0.05$ were considered significant.

\section{Determination of lost COGs}

We used the alpha- and gamma-proteobacteria species as a model system for our comparative studies because the variation of the genome size in these subdivision spans the entire size range for bacteria from $0.86 \mathrm{Mb}$ in Neorickettsia sennetsu to $5.51 \mathrm{Mb}$ in Rhodopseudomonas palustris and $0.16 \mathrm{Mb}$ for Carsonella ruddii to $7.22 \mathrm{Mb}$ in Hahella chejuensis. Furthermore, there is a large variation in lifestyles in these subdivisions, including obligate intracellular (Rickettsia and Wolbachia; Coxiella and Buchnera), facultative host-associated (Bartonella and Brucella, Legionella, Haemophilus) and free-living (Zymonas mobilis and Pseudomonas sp.) bacteria, which enables correlations between gene content and lifestyle features to be examined. We looked for significantly lost COGs: as the mean number of genes in free-living bacteria is three times that of obligate intracellular bacteria, we looked for COGs present in more than $75 \%$ of free-living bacteria, but fewer than $25 \%$ of obligate intracellular bacteria in alpha- and gamma-proteobacterial phyla (Additional file 3). We further searched for these COGs (presence or absence) within the genomes of other obligate intracellular bacteria belonging to distinct phyla. The 100 COGs lost in concert among the obligate intracellular bacteria from all phyla constitute the core of lost COGs.

\section{Gene function and evolutionary relatedness}

Under the null hypothesis that loss or conservation of COGs is due to chance, independently of their function, the classification of the COGs lost in concert into the different functional categories should be the same as that of all COGs present in bacteria. We compared the functional classifications of both lost and conserved COGs, to that of all COGs which are present in at least one bacterium, using Chi-squared test for independence $\chi^{2}$. We also looked for functions that are significantly more lost or conserved, than expected.

\section{Test of convergent evolution}

We evaluated the probability that a COG is in the core of lost COGs given that it has been lost at least by mutualists or parasites from alpha- or gamma-proteobacteria (Additional file 4). We used a randomization test to see if the observed numbers of losses in common can be attributed to random chance (Additional file 5). For that, we have simulated 2000 random losses for mutualists and parasites from alpha- and gamma-proteobacteria, among the COGs present at least in one of these bacteria. Then we counted the number of COGs lost in common and computed the proportion that it represents from the set of COGs lost by at least one bacterium. We summarized the 2000 simulated proportions in a histogram, where we add the $2.5 \%$ and $97.5 \%$ quantiles. Under random loss assumption, common loss proportions should not exceed these interval bounds.

Furthermore, under the null hypothesis that all observed convergent losses can be explained by random chance, the common loss probability $\mathrm{p}_{1}(0.0259)$ should be equal to the product

$$
\mathrm{p}_{0}=\mathrm{r}_{\alpha \text { Mutualists }} \times \mathrm{r}_{\alpha \text { Parasites }} \times \mathrm{r}_{\gamma \text { Mutualists }} \times \mathrm{r}_{\gamma \text { Parasites }}
$$

Where $r_{\theta}=$ probability that the COG is lost by bacteria of the group $\theta$ given that it is at least present in free-livings from $\alpha$ - or $\gamma$-proteobacteria (set of $\mathrm{N}=3865$ COGs).

We computed the theoretical probability $\mathrm{p}_{0}$ for any COG to be in the set of COGs lost in concert and we used the binomial distribution $\mathrm{B}(\mathrm{N}, \mathrm{p})$ to compute the probability of observing, under the hypothesis of independent phyla, at least as many convergent losses. The random variable counting COGs lost in concert among the N COGs, under the hypothesis of independent phyla, has a Binomial distribution $\mathrm{B}\left(\mathrm{N}, \mathrm{p}_{0}\right)$. We computed $\mathrm{P}(\mathrm{X} \geq 100)$, that indicates whether independence hypothesis is likely or not. Although, the real theoretical probability $\mathrm{p}_{0}$ is not given yet it can be estimated from loss proportion in each phylum. Moreover we know the behaviour of $\mathrm{P}(\mathrm{X} \geq 100)$ with respect to probability $\mathrm{p}_{0}$. It increases with $\mathrm{p}_{0}$ and reaches the critical probability 0.05 when $\mathrm{p}_{0}$ becomes greater than 0.0218 (Additional file 6). Consequently, if probability $\mathrm{p}_{0}$ is contained, with sufficiently confidence, in an interval with upper bound less than 0.0218 , then convergence is proved. Hence we use observed losses counts to give a confidence interval for each phylum loss probability, from which we deduced a confidence interval for the 
unknown probability $\mathrm{p}_{0}$. Results are given using the 95\%confidence interval of $\mathrm{p}_{0}$.

\section{Ribosomal DNA database}

We created a ribosomal RNA (rRNA) and transfer RNA (tRNA) database using BLASTn (e-value threshold of $10^{-4}$ ) for the 16S, 23S, 5S rRNA, and tRNA gene sequences from NCBI Genbank against the complete genome sequences of studied bacteria. For each ribosomal operon, the basepair coordinates corresponding to the 3' terminus of the $16 \mathrm{~S}$ rRNA and the 5' start of the 23S rRNA gene were entered into the sequence retrieval function on the created database and used to extract the Internal Transcribed Spacer (ITS) sequence. We determined the number and organization of rRNA operons, the ITS length, and the number of tRNAs (Additional file 1).

\section{Transcription, intracellular trafficking and secretory pathways}

We counted the number of genes for the COGs involved in basal transcription (90 COGs) and transcriptional regulators (111 COGs) in all studied bacteria (Additional file $8)$. We determined the ratio of transcriptional regulators, i.e., the proportion of genes that have a function as transcriptional regulators, over the total of genes involved in transcription. We compared the number of genes involved in transcriptional regulation and the ratio of transcriptional regulators between obligate intracellular, facultative host-associated and free-living bacteria using unpaired Student's t-test. We counted the number of genes assigned to the intracellular trafficking and secretory pathways (Type II, III, IV, V and VI) in all obligate intracellular bacteria (104 COGs including a list of COGs that are involved in the sixth secretory pathway [65], which is not currently described in the COGs' database) (Additional file 9). Data were analyzed using Wilcoxon rank sum test.

\section{Competing interests}

The authors declare that they have no competing interests.

\section{Authors' contributions}

PP and DR designed the research project. VM performed the data collection and analysis. MRC provided statistical and analytical support. VM, PP, and DR analyzed the data. VM and DR wrote the paper. All authors read and approved the final version.

\section{Reviewers' comments \\ Reviewer's report I}

Eugene Koonin (National Center for Biotechnology Information, NIH)

This paper reports a massive comparative-genomic analysis of parasitic and symbiotic bacteria and comes to the conclusion that their evolution is dominated, at least, quantitatively, by extensive gene loss that proceeds, in large part, along parallel routes in distant organisms. Special emphasis is made on the loss of regulatory genes that is considered to be a potentially more important process leading to pathogenicity than acquisition of "virulence factors".

I believe that the conclusions of the paper are, basically, correct. Just a few comments, not so much to criticize, but rather to put these conclusions into the context of previous research and thinking.

1. The parallel loss of genes in diverse bacterial parasites and symbionts, certainly, has been noticed before, for instance, in the context of the analysis of genome-trees constructed by gene content comparison in which the parasitic and symbiotic forms tend to cluster together (Wolf et al. Trends Genet. 2002 Sep;18(9):472-9.)

2. The paths of gene loss are partially parallel and partially divergent as also noticed on many previous occasions, just for instance: Foster J. PLoS Biol. 2005 Apr;3(4):e121

3. Parallel gene loss seems to be quantitatively dominant in the evolution of parasites and symbionts, but this is not to discount "virulence factors" (generally viewed) that can be qualitatively critical. Even one such gene can make a big difference like, for instance, ATP/ADP translocase in Rickettsia and Chlamydia.

Authors' response: The authors thank the reviewer for these comments. We have referred to these works in the paper.

\section{Reviewer's report 2 \\ Nicolas Galtier (CNRS-Université Montpellier II)}

This manuscript provides a thorough analysis of $>300$ bacterial genomes, distinguishing free-living from (various levels of) host-dependent species. It is reported that parasitic and mutualistic bacteria have a higher AT-content, a lower number of ribosomal RNA genes and intact ribosomal operons, and have experienced massive gene loss in a non-independent way - host-dependent species from distinct phyla tend to lose/retain the same genes and functions.

I found the analysis well-conducted, and the results interesting. Not everything is new, of course, but this is the first overall picture of the situation, as far as I know, and I learnt much by reading this piece. Here are a couple of comments. 
The discussion about rRNA operon, growth rate and lifestyle appears a bit unclear to me. The relationship between doubling time and number of rRNA operons seems pretty strong (but unfortunately not shown, figure 5 being difficult to decipher). My guess would be that growth rate, which everybody says is primarily limited by protein synthesis, is the leading player here. So the question could be: why would intracellular species evolve a slower growth rate than free-living bacteria? The authors invoke environmental stability and reduced number of genes, but the connection is not obvious. I would suggest that growth rate is under more subtle selective pressure in a host-dependent species than in a free-living species. This is because the growth rate of a parasite/mutualist is (presumably) strongly related to its virulence. Because of the two-level selection process - between individuals within a host vs. between colonies of distinct hosts - growth rate in host-dependent bacteria could be limited to avoid too strong, detrimental virulence.

Authors' response: Intracellular genomes encounter elevated genetic drift resulting from relaxed selection on many genes and from radical change in population structure that results in lowered efficacy of selection on genes [66-68]. It has been suggested that the occurrence of multiple typical operons may be important in the ability of bacteria to respond to changing growth conditions [43]. Living continuously within the host eliminates the extreme environmental fluctuations encountered by freeliving bacteria [24]. Selective coefficients for the maintenance of genes for regulation and for rRNA genes may be reduced in an intracellular environment, resulting in the loss of these genes.

We found a significant negative correlation between generation time on one side and the number of rRNA operons and transcriptional regulators on the other side. Growth rate is linked on one hand to the number of rRNA operons which are the principle apparatus for translation and to the regulation of transcription on the other hand. Hence, as you said growth rate is primarily limited by protein synthesis. The slower growth rate of intracellular bacterial parasites may be important as these bacteria have to dissimulate in order to avoid immune system. Add to this growth leads to host-cell lysis in Chlamydia for example, thus to the loss of the host supply. Therefore, slow growth for parasitic bacteria may be essential to prolong their life within cell. The slow growth rate is also beneficial for mutualistic bacteria. Mutualists and their host exchange gene products, because of this complementary and mutual dependence, mutualistic bacteria have to synchronize their metabolism with that of their host. Indeed, symbiotic relationship implicates that the endosymbionts and the host cell live in concert. Altogether, slow growth may be under more selective pressure in host-dependent bacteria than in free-living bacteria.

Reviewer: Reporting that parasitic and mutualistic bacterial species have distinct, irreversible gene-loss signatures, the authors question the scenario invoking parasitism as an intermediate step before mutualism, which is a good point. They do not, however, comment on the fact that "global" markers of host-dependence (AT-content, number of genes, number of rRNA operons) are more extreme in mutualists than in parasites. I would tend to interpret this as a consequence of higher stability in time of mutualistic associations, as compared to parasitism, which seems to make sense. This is good self-corroboration for the life style annotations used in this study.

Authors' response: Thank you for this remark. We have demonstrated that there is a significant difference in genome content between parasites and mutualists due to the differential gene loss in relation with their lifestyles. Add to this the sequestration of these intracellular genomes limits their capacity for lateral gene transfer, which renders gene loss irreversible. Altogether, these observations suggest that mutualism and parasitism are two distinct host-relationships supported by significantly different sets of functions. The difference between mutualists and parasites is significant for many functions, especially for amino acids transport and metabolism that represent a higher fraction of the mutualistic genomes than in the parasitic genomes.

Relevant genomic studies about mutualists, like Buchnera spp., revealed the stability of these genomes [21]. This genomic stasis (absence of chromosome rearrangements and gene acquisition) is likely attributable to the loss of phages, repeated sequences, and recA. Hence, the loss of genetic elements that mediate recombination is responsible for the genome stability. In contrast, genome analyses of parasitic genomes like Rickettsiae, showed gene rearrangements [39] and genome shuffling [69]. Moreover certain genomes contain plasmids and present evidence for lateral gene transfer $[70,71]$. Even though these events are rare in obligate intracellular bacteria comparing to free-living bacteria, they are more important in parasitic genomes than in symbiotic genomes. Altogether, these observations confirm that mutualistic genomes present a higher level of genome stability than parasitic genomes.

Reviewer: By the way: where do these annotations come from? Is there a database for bacterial ecology?

Authors' response: Considering the large amount of bacterial genomes, we were interested in a possible relationship between the phenotype and the genome. We doubt there is a database for bacterial ecology. We made an 
exhaustive literature review looking for information about bacterial lifestyle. We checked for the habitat of these bacteria and eventual eukaryotic cell-dependency. Bacterial classification is indicated in additional file 1.

Reviewer: One major result of the paper is the discovery of non-independent gene loss in various, distantly related, transitions from free-living to host-dependent life style. This result, however, is perahps not surprising, knowing that essentiality varies across genes - some can be lost, some can not, irrespective of life style. The authors partly account for this by restricting the statistical test to the set of genes lost at least once, so that essential genes are not considered in this analysis. Even among "losable" genes, however, the probability of gene loss irrespective of life style could vary. I would suggest to perform a control analysis in which host-dependent genomes would be replaced by small, free-living genomes - several free-living alpha and gamma proteobacteria have less than 2500 genes. It could be good to know what is specific to hostdependence-associated genome reduction, as compared to "random" (whatever it means) genome reduction.

Authors' response: The process of genome reduction and gene loss is well-known for obligate intracellular bacteria $[8,10,20,72]$. The aim of this paper was not to reproduce such results but to test for an eventual convergent evolution, characterized by a non-random loss induced by the common phenotype.

According to your suggestion, we have performed the control analysis to verify that the 100 lost COGs are specific to the reductive evolution of obligate intracellular bacteria. For that we have separated free-living bacteria into two groups: free-living small genomes and free-living large genomes using the cut-off of $2.92 \mathrm{Mb}$ which is the mean genome size of facultative host-associated bacteria. In order to make the comparison between phylogenetically close relatives, we have treated the only phyla where there were small and large genomes. Genome sizes are given in additional file 1. We got 8 phyla Alpha-, Beta- and Gammaproteobacteria, Clostridia, Lactobacillales, Bacillales, Actinobacteria, and Cyanobacteria, which represent a total of 168 free-living to include in the analysis. In each phylogenetic group, we identified COGs that are lost by $75 \%$ of the small free-living and conserved in more than $25 \%$ of the large free-living. First, we looked for COGs that are lost in common, i.e. by small free-living from more than one phylum. Second, in order to see if the 100 lost COGs are specific to the obligate intracellular reductive evolution, we studied the losses of small free-living bacteria. Thus, we compared their loss distribution for a COG in the set of the 100 COGs to the loss distribution for a COG in all the other COGs (among COGs lost at least once in small free-living), using a Chi-squared test for independence.
We found no COG lost in common by all small free-living from the 8 phylogenetic studied groups. Similarly, we didn't find a COG that is lost in concert by small free-living from 7 or 6 groups. Thus no convergence phenomenon occurs within these phylogenetic groups, and the hypothesis of independent loss for small free-living cannot be rejected. The majority of the losable COGs are lost by only one phylogenetic group (Additional file 10). Freeliving small genomes lose COGs from the set of 100 COGs or from the set of other COGs without difference (Chi-squared test for independence $\chi^{2}=3.695, \mathrm{df}=2, \mathrm{p}$ value $=0.158$ ). Thus, in the free-living loss process, there is no significant preference for the set of 100 COGs that we found associated to the obligate intracellular genome's reduction. Consequently, we can deduce that these 100 COGs are specific to the reductive evolution of obligate intracellular genomes.

\section{Reviewer's report 3 Jeremy Selengut (The Institute for Genomic Research)}

This work presents a useful overall comparative analysis and comparison of the genomic content of free-living, host-associated and obligate intracellular organisms. The well-known observation that small genome sizes are correlated with host-association is supported with concrete data, but more importantly, this is dissected with respect do different types of host-associated lifestyle. Difference between mutualists and parasites are delineated, and most importantly, commonalities are found between the classes of genes and changes in rRNA operons that are observed in many phylogenetically independent cases of adaptation to a host-associated lifestyle.

Unfortunately, in its current form, this manuscript suffers from many faults in language, logic, organization, data analysis and data presentation. I have offered extensive comments on these issues and sincerely hope that these deficiencies can be improved. None of these issues is fatal, and I expect that with an improved manuscript I will be able to provide a more positive endorsement in the public commentary accompanying its publication.

Authors' response: Thank you for the time you have spent revising the manuscript. Thank you for all the valuable comments you have addressed to us. Please find attached the manuscript revised according to your remarks. We have made the corrections in language and data presentation. We tried to clarify some areas of the method and data analysis. Hope that this version of the manuscript conforms to the requirements and can get your positive support. 


\section{Final Review}

Reviewer: The authors, in their attempt to probe into the nature of genome reduction in obligate intracellular (OI) "specialists", lay out a stepwise model from large free-living organisms to somewhat reduced host-associated organisms finally to OI organisms with their small genomes. On the one hand, this model is inarguable, in order to go from large to small, an intermediate medium state must be passed through. A pertinent question, however, is whether currently observable host-associated, moderately reduced species are representative in terms of their detailed gene content of that intermediate state which OI organisms passed through. Are the host-associated organisms of today the OI organisms of the future, or did today's OI organisms pass through a different kind of intermediate state on their evolutionary pathway?

Authors' response: The purpose of this paper was to correlate genomic features with phenotype i.e. the small genome size and gene content with the bacterial lifestyle. For that we classified bacteria in 3 large communities on the basis of their lifestyles then we compared their genomic contents. According to previous relevant papers, small genome is not an ancestral state. Molecular phylogenetic studies and genome analyses showed that the small reduced genomes derived from large genomes through massive gene loss [5-8,20,73,74]. Our analysis of genome content shows that facultative host-associated bacteria constitute a large community of bacteria that we can consider as intermediate because their genome content is smaller than that of free-living bacteria and larger than that of obligate intracellular bacteria (Figure 3). Moreover, genome analysis of obligate intracellular bacteria of Rickettsia spp. revealed the presence of degraded genes and gene remnants [41]. The presence of gene remnants in these reduced genomes constitutes molecular fossils that witnesses for the gradual genome degradation leading to specialized intracellular bacteria, and confirms the role of intermediate stage that we can attribute to the facultative host-associated bacteria. In fact, our results confirm the simple evidence that the more genes are lost the more a bacterium becomes dependent of its host.

Reviewer: A separate question to be addressed is whether all OI organisms, irrespective of the specifics of the evolutionary paths they have travelled to get there, have more or less arrived at the same end point. There are two ways to look at this question, one could try to determine whether the set of remaining genes is the same across all OI organisms, or one could ask whether the set of genes lost from free-living ancestors is similar. The former method is simpler, more commonly essayed, but the answers it provides are much clouded by the lineage-specific genes which are what make each OI organism unique and adapted to its particular host. The latter tack is the focus of this work and requires a bit more effort to reconstruct an accounting of the lost genes.

Authors' response: Our analysis considers the lost and the remained genes. One, we could demonstrate that the loss event concerns the same set of COGs and that is what we described as convergent reductive evolution. Second, we compared the gene content between obligate intracellular bacteria, parasites vs. mutualists, and we showed that gene inventories are significantly different, because the remaining genes reflect the host-relationship, harmful or beneficial, respectively.

A future approach that we would like to develop consists of reconstructing the ancestral genomes then describing the evolution of genes using the phylogenetic profile. We would relate the history of gene loss and gene gain of each phylum more precisely in the evolutionary time scale.

Reviewer: In the results section of the abstract it is stated that the observation of fewer rRNA genes, split rRNA operons and fewer transcriptional regulators are linked to slower growth rates. I find this usage of the term "linked" unfortunate, as nothing over and above a statistical corellation is presented here. These four measurables are all corellated to one another, the OI lifestyle and any number of other factors characteristic of OI organisms. It may be that there is a rationale to explain a linkage between slow growth rates, rRNA operons and transcriptional regulators, but the authors have neither spelled out that rationale nor suported this linkage as a significant "result" of their work. On a similar note, the results also state that the specialization is an "irreversible phenomenon characterized by translation modification and massive gene loss..." That specialization is irreversible in OI organisms considering their genetic isolation from a gene pool for lateral gene transfer has been suggested in other work and is quite reasonable, but it can hardly be construed as a result of this study, and the particular connection to "translation modification" (changes in the apparatus of translation i.e. rRNAs - author's comment) is unsupported.

Authors' response: The PCA in Figure 5 shows that the obligate intracellular reduced genomes have few genes for transcriptional regulation, few rRNA operons and that they do need long time for growth. On the contrary, the fast-growing free-living bacteria have more genes involved in the regulation of transcription and more rRNA operons. We have done a multiple regression analysis to test for correlation between the 3 factors (growth time, transcriptional regulation and rRNA operon numbers). The multiple regression analysis showed that there is a significant relation between the phenotypic character which is the growth time, and the 2 other genomic features. 
In what concerns irreversibility, genome size and gene repertoire can increase through gene acquisition, i.e. lateral gene transfer and gene duplication, and conversely, decrease by deletion $[3,4]$. It is not surprising that the genomes of obligate intracellular bacteria includes the smallest genome of any characterized bacteria, that of Candidatus Carsonella ruddii, an endosymbiotic Gammaproteobacteria. In fact, the dynamics of bacterial genomes are affected by their niches. On one hand, specialization to an intracellular lifestyle implies a genetic isolation characterized by the diminution of lateral gene transfer. Indeed, a phylogenomic study has shown that bacteria from different phyla cluster together according to their waterborne lifestyle [13]. Audic et al., have quantified the lateral gene transfer events and have concluded that bacterial communities living in water have the highest percentage of LGT, whereas intracellular bacteria have the lowest percentage of LGT. On the other hand, Andersson et al. $[72,75]$ and Moran et al. $[8,76]$ have studied the genome evolution by gene loss, in the parasites in Alphaproteobacteria and in the endosymbionts in Gammaproteobacteria. Altogether, the reduced genome that results from or follows the restriction of bacteria to a special niche implies massive gene loss that is not compensated by the acquisition of foreign DNA (LGT). Thus, the severe gene loss we described in obligate intracellular genomes comparing to free-living bacteria, may represent an irreversible evolutionary trajectory that constrains existence outside a eukaryotic cell, and limits transitions in lifestyles (e.g. parasitic versus mutualistic associations with hosts) $[7,47]$. Indeed, the irreversibility is not a result of our paper, but it is an important argument to support the different evolutionary fates of mutualists' and parasites' genomes. Irreversibility is essential in the description of the model we propose: "the one-way road specialization".

Finally it has been suggested that recombination events concerning the duplicated rRNA operons induced genome shuffling and contributed to the rickettsial genome evolution $[39,40]$. We could show that the altered structure of rRNA operons concerns more than one host-dependent lineage. That's why we judged important to mention this result as it helps in the understanding of one of the mechanisms of evolution.

Reviewer: The abstract states that this work identifies the loss of "100 genes" in OI organisms. This is not strictly true in the sense of 100 individual, named orthologous genes, rather, they have identified 100 gene functions represented by 100 different COGs (clusters of orthologous groups). Many of these COGs have more than one representative in free-living organisms. Members of these 100 orthologous groups are absent from OI organisms and nearly universal in free-living organisms. Finally, that the statement that mutualists and parasites have lost distinct sets of genes is paired with statements about which types of genes are retained is curious and confusing.

Authors' response: Our analysis consisted on comparing bacterial genomes from different lifestyles on the basis of their genome content. We used the classification of the genes in the functional categories as defined in the COG database $[60,61]$. Our method was based on the comparaison of:

(i) the number of genes for each category of COG (copy number of genes) (Table 1)

(ii) and the number of COG present or absent in each bacteria.

Thus, considering the presence or absence of COGs we identified 100 orthologous genes lost in obligate intracellular bacteria and present in free-living bacteria (Table 4). Thank you for this precision, we have highlighted this notion in the abstract.

When comparing the number of genes, free-living bacteria have more genes than obligate intracellular bacteria (Additional file 2), and the difference is more than 100 genes. Thus, obligate intracellular bacteria have lost more than the core of 100 lost COGs. Obviously, we can say that these additional losses are specific to the evolutionary history of each species. Our comparison of the gene contents of mutualists and parasites showed that the gene inventories are specific to each lifestyle. This suggests that the additional losses we talk about are in fact specific to the type of host-relationship.

Reviewer: In their abstract conclusion, the authors state that gene loss rather than acquisition of virulence factors has been a driving force in the adaptation of parasites to eukaryotic cells. I find this a bit hard to take, considering that there is no explicit study of virulence factors in this work, in fact the only mention of virulence factors is in the manuscript's conclusion where a single reference supports a statement about the occurrence of genes named virulence factors in free-living organisms compared to pathogenic bacteria, a statement whose character has the distinct odor of transitive annotation error about it.

Authors' response: In what concerns the driving force, what we claim makes a lot of sense on evolutionary point of view. Human bacterial pathogens are highly specialized bacteria their evolution obeys to the allotropic model of speciation by Mayr [77]. When specializing to an intracellular lifestyle, bacteria lose their capabilities to survive in another niche because of the loss of genes and genetic isolation. Thus the overall consequence of allotropic speciation is genome reduction and gene loss. The reversibility 
of this phenomenon has never been demonstrated and is basically against evolutionary principle see [78]. We didn't study the virulence factors in this work but the mention in the manuscript's conclusion can be considered as a prospect. Actually, the evolutionary history of virulence factors would be very interesting to explore in a further work.

Reviewer: To support the statement (Results and Discussion, first line) that "Host-dependent bacteria typically have a smaller genome size and fewer genes compared to their close relatives in the same phylum.", Additional file 2 is included. Unfortunately, that plot only establishes that host-dependent organisms trend towards smaller size within phyla, but makes no statements about organisms which are close relatives in the same phylum. A phylum is a pretty broad taxonomic grouping. In fact the authors repeatedly use the phrase "close relatives" when trying to relate free-living and host-associated organisms while in fact basing this closeness on broad taxonomic categories and never holding up a specific example. An analysis based on a tree of life (for instance, Wu \& Eisen, 2008) would be much more useful. Specific examples would be useful, i.e. what specific free-living organisms can be held up as the closest relatives of specific OI organisms and what can be concluded about them?

Authors' response: The phylogenetic close relatives are determined according to the current bacterial taxonomy and standard prokaryotic phylogeny, based on sequence similarity of $16 \mathrm{~S}$ rRNA. In agreement with previous phylogenomic studies [11-13], our work confirms that based on the genome content and the bacterial lifestyle, bacteria may be close relatives to distant phylogenetically related bacteria (on the basis of the 16S rRNA). Thus on the phylogenetic tree in figure 1 we can appreciate the convergent evolution, i.e. similar genomic features (like gene loss and alteration of rRNA operons) occurring in bacteria from distinct phyla but similar habitat.

Reviewer: One of the central claims of this work is that genome-reductive adaptation of distantly related organisms to varied intracellular environments is convergent. That is to say, the same sets of gene functions are lost (as represented here by COGs). In order to support this claim it is not sufficient to tally the number of COGs which are lost in all or most OI organisms, considering the total amount of genes lost, some number will be lost in common. The task then is to determine whether the observed number of concerted losses of the same function is statistically significant as compared to a random loss model. The representation of the statistical methods used to prove this point in the main body of the paper and the caption to Additional File 5 are vague, but are detailed in the methods section. Unfortunately, insufficient detail and more important, clarity, is provided in the methods to allow one to fully understand the procedure or to allow replication of their results. Part of the murkiness in the description may result from difficulties in the use of English, for instance the many missing articles, and does "commonly lost" mean "often observed to be lost" or "lost in concert among all test groups"? A more basic question is whether the overall approach, a comparison of only alpha and gamma proteobacterial mutualists and parasites is a valid one. The authors should have spent more effort in the main section of the manuscript outlining why this approach was chosen over other possibilities, and why the resulting statistical significance value proves the point they are trying to prove. Why are they focussing on cases where a COG is "lost by bacteria of the group $\theta$ given that it is at least present in mutualists or parasites from $\alpha$ or $\gamma$-proteobacteria"? This would be those COGs which are not among the "core of lost COGs" because they are present in one of these OI classes. The very next sentence says that this calculation is used to compute the probability for any COG to be "in the set of commonly lost COGs". How is this done?

Authors' response: We have modified the method section concerning the test of convergence in order to be more explicit. The "commonly lost" COGs are "COGs lost in concert among all test groups", i.e. core of lost COGs. Alpha and gamma proteobacteria are the unique phyla containing both free-living and obligate intracellular bacteria, in sufficient species number to allow statistical comparative studies to be done. The obligate intracellular bacteria from these two phyla represent a total of 25 bacteria over the 40 studied obligate intracellular bacteria. Add to this, we didn't extrapolate the results of these two phyla to the rest of obligate intracellular bacteria but we searched for the COGs that we found lost in concert among the obligate intracellular bacteria from alpha and gamma Proteobacteria, in the obligate intracellular bacteria of other phyla. Thus the 100 COGs we retained are absent from all obligate intracellular bacteria from different phyla. With the growing number of genome sequences, we can expect to get more sequences for obligate intracellular and free-living bacteria in all phyla, in order to make comparative genomic analyses including phyla remaining unstudied to date. We aimed to prove the non-independent gene loss between phyla, i.e. the obligate intracellular bacteria from different phyla tend to lose the same COGs or they tend to lose no COG in common. For that, we first calculated the probability for an obligate intracellular bacterium to lose a COG among the 969 COGs lost at least by mutualists or parasites from $\alpha-$ or $\gamma$-proteobacteria (Additional file 4). We obtained [0.0446, 0.0847 ] as $95 \%$-confidence interval of p0. Then we calculated the probability $\mathrm{P}(\mathrm{X} \geq 100)$ with $\mathrm{X}$ having the Bino- 
mial distribution B $(969, \mathrm{p}=0.0847)$, this probability was less than 0.05 .

Consequently the same holds true for any probability $\mathrm{p}$ in the 95\%-confidence interval of $\mathrm{p}_{0}$ (Additional file 11). This indicates that the obligate intracellular bacteria do not lose COGs independently and thus proves convergent loss phenomenon because the observed common loss probability $\mathrm{p}_{1}(0.1032)$ was significantly greater than the probability $\mathrm{p}_{0}\left(\mathrm{p}_{0} \leq 0.0847\right.$ with $95 \%$ confidence $)$ of loss in common under the hypothesis of independent gene loss between phyla. Second, we did not restrict our analysis to the set of COGs lost by obligate intracellular bacteria (969 COGs), but we considered also the whole losable COGs, i.e. COGs present in free-living bacteria from $\alpha-$ or $\gamma$-proteobacteria (3865 COGs). We obtained [1.6 $\times 10^{-}$ $\left.4,3.7 \times 10^{-4}\right]$ as $95 \%$-confidence interval of $\mathrm{p}_{0}$. The probability $\mathrm{P}(\mathrm{X} \geq 100)$ with $\mathrm{X}$ having the Binomial distribution $\mathrm{B}\left(3865,3.7 \times 10^{-4}\right)$ was once again less than 0.05 . In the final version of the manuscript we only kept the latter test considering the losable COGs (Additional file 6).

Reviewer: The authors make much of their correlations between various calculated values and growth rates in particular. For instance, they state that they find a "significant negative correlation between generation time on one side and the number of rRNA operons and transcriptional regulators per Mb on the other side." And then state that all of these are correlated with the OI lifestyle. Of all of the measurables in this work, it is the growth rate data which is most indirect and subject to bias. The authors have compiled growth data from other compilers of such data (in a way that is not easily traceable) and from primary literature from a wide variety of organisms growing under many different conditions with varying relationships to the conditions in which they were evolved to live. They have binned these data into only three discrete categories (fast, medium and slow) and represented those categories by three discrete numbers for their PCA analyses. Considering the highly correlated nature of all of the observables under study here and the over-processed and indirect nature of the growth data, I find little of value is added to this work by its inclusion.

Authors' response: We disagree with this statement. This is the first work of this nature published to date, and it may be improved latter. Actually, introducing a wide scale analysis of growth time, transcriptional regulators and ribosome is a real contribution. The ribosome is probably a critical point in the evolution of specialized bacteria. For that, we made an exhaustive literature search looking in previous papers for exact experimentally time of growth for bacteria. And we have asked two international reference collections, Pasteur and CCUG, for help about these data. They agreed that there are a lot of problems to deter- mine precisely the time of growth of bacteria. Thus we looked in literature and in CCUG website http:// www.ccug.se/default.cfm?navID=1 for information concerning the doubling time, or the generation time or the colony observation or plaque formation (We have mentioned all the references we used in additional file 1). The time of growth is given for bacteria in their optimal growth conditions known nowadays: plate growth or cell cultures (for fastidious bacteria). We grouped the studied bacteria into 3 categories fast growing (24-48 hours), median ( 3 to 7 days) and slow growing fastidious bacteria (more than 7 days). We proposed approximate numbers for the 3 categories $(2,5$ and 10$)$ that reflect the 3 ordered levels of the experimental growth time. The Principal Component Analysis (PCA) revealed similar behaviors of bacteria on the basis of the gene count of transcriptional regulators, rRNA operon numbers and growth time. The task was difficult to determine precisely the growth time but we consider that it is worthy doing it because it revealed an important correlation between translation, transcription and time of growth. Hope that future experimental works will give more precise determination of generation time that reflects the real growth time of these bacteria.

\section{Additional material}

\section{Additional file 1}

Genome information data.

Genome information data.

Click here for file

[http://www.biomedcentral.com/content/supplementary/17456150-4-13-S1.pdf]

\section{Additional file 2}

Trends between genome size and gene count in different bacterial phyla.

Trends between genome size and gene count in different bacterial phyla. Columns correspond to the genome size (left axis), and the points correspond to the gene count (right axis). Red and blue colours correspond to host dependent (HD) and free-living (FL) bacteria, respectively. Other phyla: Aquifex, Thermotoga, Chlorobium, Dehalococcoides, Deinococci, Thermus, Fusobacteria, and planctomyces. Taxa are listed in Additional file 1.

Click here for file

[http://www.biomedcentral.com/content/supplementary/17456150-4-13-S2.pdf]

\section{Additional file 3}

Schematic representation of strategy used to identify essential and lost COGs.

Schematic representation of strategy used to identify essential and lost COGs. FL corresponds to free-living and OI corresponds to obligate intracellular bacteria.

Click here for file

[http://www.biomedcentral.com/content/supplementary/17456150-4-13-S3.pdf] 


\section{Additional file 4}

Comparison of the sets of lost COGs.

Comparison of the sets of lost COGs. Venn diagram shows the number of shared and group-specific COGs lost in obligate intracellular bacteria and conserved in their close free-living relatives in alpha- and gamma-proteobacteria. Mycobacterium leprae lost only 63\% of these COGs, however its genome content is rapidly degrading according to the high number of pseudogene [27].

Click here for file

[http://www.biomedcentral.com/content/supplementary/17456150-4-13-S4.pdf]

\section{Additional file 5}

Distribution of the common loss proportion, simulated from 2000 re-samplings.

Distribution of the common loss proportion, simulated from 2000 resamplings. The number of COGs lost by each phylum is fixed and equals the observed loss numbers. Red dashed lines represent the $2.5 \%$ and 97.5\% quantiles and blue line indicates the observed common loss proportion. 100 COGs were lost in concert among the obligate intracellular bacteria over the 969 COGs that are lost by at least one of the studied bacteria, which give a proportion of 0.1032 (100/969). The number of common COGs lost was significantly more important than expected if the loss were random (Randomization test, $n=2000, \mathrm{p}<10^{-6}$ ).

Click here for file

[http://www.biomedcentral.com/content/supplementary/17456150-4-13-S5.pdf]

\section{Additional file 6}

Probability of losing at least 100 COGs in common Curve describing the probability of losing at least 100 COGs in common with respect to the theoretical probability of random loss (p0). Probability of losing at least 100 COGs in common Curve describing the probability of losing at least 100 COGs in common with respect to the theoretical probability of random loss $(p 0)$. The red point corresponds to the probability-threshold under which the hypothesis of independent loss between phyla is rejected (with $\alpha=5 \%$ ).

Click here for file

[http://www.biomedcentral.com/content/supplementary/17456150-4-13-S6.pdf]

\section{Additional file 7}

Mean number of genes per Mb encoding for intracellular trafficking.

Mean number of genes per $\mathrm{Mb}$ encoding for intracellular trafficking ${ }^{*} \mathrm{p}$-values $<0.05$ are shown in bold to indicate significant differences between mutualists and parasites (Wilcoxon rank sum test).

Click here for file

[http://www.biomedcentral.com/content/supplementary/17456150-4-13-S7.doc]

\section{Additional file 8}

COGs involved in transcription.

COGs involved in transcription.

Click here for file

[http://www.biomedcentral.com/content/supplementary/17456150-4-13-S8.doc]

\section{Additional file 9}

COGs involved in intracellular trafficking and secretion. COGs involved in intracellular trafficking and secretion.

Click here for file

[http://www.biomedcentral.com/content/supplementary/17456150-4-13-S9.doc]

\section{Additional file 10}

Distribution of COGs lost by small free-living bacteria among the set of 100 COGs lost in common by obligate intracellular bacteria and among all other COGs.

Distribution of COGs lost by small free-living bacteria among the set of 100 COGs lost in common by obligate intracellular bacteria and among all other COGs.

Click here for file

[http://www.biomedcentral.com/content/supplementary/17456150-4-13-S10.pdf]

\section{Additional file 11}

Probability of losing at least 100 COGs in common among the 969 COGs lost at least by one obligate intracellular bacterium. Probability of losing at least 100 COGs in common among the 969 COGs lost at least by one obligate intracellular bacterium. Curve describing the probability of losing at least 100 COGs in common with respect to the theoretical probability of random loss ( $p 0)$. The red point corresponds to the probability-threshold under which the hypothesis of independent loss between phyla is rejected (with $\alpha=5 \%$ ).

Click here for file

[http://www.biomedcentral.com/content/supplementary/17456150-4-13-S11.pdf]

\section{Acknowledgements}

Authors thank E. Pardoux for advice on statistical analyses, C. Notredame and P-E. Fournier for discussions and comments on the manuscript, and $\mathrm{S}$. Audic and $\mathrm{G}$. Fournous for technical support.

Authors gratefully acknowledge the thoughtful comments, valuable suggestions, and helpful criticisms of the reviewers

\section{References}

I. Nakabachi A, Yamashita A, Toh H, Ishikawa H, Dunbar HE, Moran NA, et al:: The I60-kilobase genome of the bacterial endosymbiont Carsonella. Science 2006, 3 I 4:267.

2. Casjens S: The diverse and dynamic structure of bacterial genomes. Annu Rev Genet 1998, 32:339-377.

3. Ochman H, Moran NA: Genes lost and genes found: evolution of bacterial pathogenesis and symbiosis. Science 200I, 292: 1096-1099.

4. Konstantinidis KT, Tiedje JM: Trends between gene content and genome size in prokaryotic species with larger genomes. Proc Natl Acad Sci USA 2004, I 0 I:3160-3165.

5. Sallstrom B, Andersson SG: Genome reduction in the alpha-Proteobacteria. Curr Opin Microbiol 2005, 8:579-585.

6. Andersson SG, Kurland CG: Reductive evolution of resident genomes. Trends Microbiol 1998, 6:263-268.

7. Moran NA, Wernegreen JJ: Lifestyle evolution in symbiotic bacteria: insights from genomics. Trends Ecol Evol 2000, 15:32I-326.

8. Moran NA, Mira A: The process of genome shrinkage in the obligate symbiont Buchnera aphidicola. Genome Biol 200I, 2:RESEARCH0054

9. Zomorodipour A, Andersson SG: Obligate intracellular parasites: Rickettsia prowazekii and Chlamydia trachomatis. FEBS Lett 1999, 452:II-I5. 
10. Darby AC, Cho NH, Fuxelius HH, Westberg J, Andersson SG: Intracellular pathogens go extreme: genome evolution in the Rickettsiales. Trends Genet 2007, 23:51 I-520.

II. Wolf YI, Rogozin IB, Grishin NV, Koonin EV: Genome trees and the tree of life. Trends Genet 2002, 18:472-479.

12. Suen G, Goldman BS, Welch RD: Predicting prokaryotic ecological niches using genome sequence analysis. PLOS ONE 2007 , 2:e743

13. Audic S, Robert C, Campagna B, Parinello H, Claverie JM, Raoult D, et al:: Genome analysis of Minibacterium massiliensis highlights the convergent evolution of water-living bacteria. PLoS Genet 2007, 3:e I38.

14. Felsenstein J: PHYLIP (Phylogeny Inference Package) version 3.5c. 1993 .

15. Saitou N, Nei M: The neighbor-joining method: a new method for reconstructing phylogenetic trees. Mol Biol Evol 1987, 4:406-425.

16. Itoh T, Martin W, Nei M: Acceleration of genomic evolution caused by enhanced mutation rate in endocellular symbionts. Proc Natl Acad Sci USA 2002, 99: 12944 - 12948.

17. Wernegreen JJ, Degnan PH, Lazarus AB, Palacios C, Bordenstein SR: Genome evolution in an insect cell: distinct features of an ant-bacterial partnership. Biol Bull 2003, 204:221-231.

18. Rocha EP, Danchin A: Base composition bias might result from competition for metabolic resources. Trends Genet 2002 I 8:291-294

19. Haft DH, Selengut JD, Brinkac LM, Zafar N, White O: Genome Properties: a system for the investigation of prokaryotic genetic content for microbiology, genome annotation and comparative genomics. Bioinformatics 2005, 21:293-306.

20. Mira A, Ochman H, Moran NA: Deletional bias and the evolution of bacterial genomes. Trends Genet 200I, I 7:589-596.

21. Tamas I, Klasson L, Canback B, Naslund AK, Eriksson AS, Wernegreen J], et al.: $\mathbf{5 0}$ million years of genomic stasis in endosymbiotic bacteria. Science 2002, 296:2376-2379.

22. Moran NA, Plague GR: Genomic changes following host restriction in bacteria. Curr Opin Genet Dev 2004, I 4:627-633.

23. Wernegreen J]: For better or worse: genomic consequences of intracellular mutualism and parasitism. Curr Opin Genet Dev 2005, I 5:572-583.

24. Moran NA: Microbial minimalism: genome reduction in bacterial pathogens. Cell 2002, I 08:583-586.

25. Altschul SF, Madden TL, Schaffer AA, Zhang J, Zhang Z, Miller W, et al.: Gapped BLAST and PSI-BLAST: a new generation of protein database search programs. Nucleic Acids Res 1997 25:3389-3402

26. Nelson KE, Paulsen IT, Heidelberg JF, Fraser CM: Status of genome projects for nonpathogenic bacteria and archaea. Nat Biotechnol 2000, 18:1049-1054.

27. Cole ST, Eiglmeier K, Parkhill J, James KD, Thomson NR, Wheeler $\mathrm{PR}$, et al.: Massive gene decay in the leprosy bacillus. Nature 200I, 409: I007-I0II.

28. Fraser CM, Norris SJ, Weinstock GM, White O, Sutton GG, Dodson $\mathrm{R}$, et al.: Complete genome sequence of Treponema pallidum, the syphilis spirochete. Science 1998, 28 I:375-388.

29. Gomez-Valero L, Rocha EP, Latorre A, Silva FJ: Reconstructing the ancestor of Mycobacterium leprae: the dynamics of gene loss and genome reduction. Genome Res 2007, I 7: I I 78- I I85.

30. Horn M, Collingro A, Schmitz-Esser S, Beier CL, Purkhold U, Fartmann $B$, et al.: Illuminating the evolutionary history of chlamydiae. Science 2004, 304:728-730.

31. Seshadri R, Paulsen IT, Eisen JA, Read TD, Nelson KE, Nelson WC, et al.: Complete genome sequence of the Q-fever pathogen Coxiella burnetii. Proc Natl Acad Sci USA 2003, 1 00:5455-5460.

32. Mushegian AR, Koonin EV: A minimal gene set for cellular life derived by comparison of complete bacterial genomes. Proc Natl Acad Sci USA 1996, 93:10268-10273.

33. Hutchison CA, Peterson SN, Gill SR, Cline RT, White O, Fraser CM, et al: Global transposon mutagenesis and a minimal Mycoplasma genome. Science 1999, 286:2165-2169.

34. Koonin EV: Comparative genomics, minimal gene-sets and the last universal common ancestor. Nat Rev Microbiol 2003 I:I27-I36.

35. Klasson L, Andersson SG: Evolution of minimal-gene-sets in host-dependent bacteria. Trends Microbiol 2004, I 2:37-43.
36. Glass Jl, ssad-Garcia N, Alperovich N, Yooseph S, Lewis MR, Maruf M, et al.: Essential genes of a minimal bacterium. Proc Natl Acad Sci USA 2006, I03:425-430.

37. Gil R, Silva FJ, Pereto J, Moya A: Determination of the core of a minimal bacterial gene set. Microbiol Mol Biol Rev 2004, 68:518-537.

38. Krawiec S, Riley M: Organization of the bacterial chromosome. Microbiol Rev 1990, 54:502-539.

39. Andersson SG, Stothard DR, Fuerst P, Kurland CG: Molecular phylogeny and rearrangement of rRNA genes in Rickettsia species. Mol Biol Evol 1999, I6:987-995.

40. Blanc G, Ogata H, Robert C, Audic S, Suhre K, Vestris G, et al: Reductive genome evolution from the mother of Rickettsia. PLoS Genet 2007, 3:el4.

4I. Ogata H, Audic S, Renesto-Audiffren P, Fournier PE, Barbe V, Samson $D$, et al:: Mechanisms of evolution in Rickettsia conorii and $\mathbf{R}$. prowazekii. Science 200I, 293:2093-2098.

42. Foster J, Ganatra M, Kamal I, Ware J, Makarova K, Ivanova N, et al.: The Wolbachia genome of Brugia malayi: endosymbiont evolution within a human pathogenic nematode. PLOS Biol 2005, 3:el2I.

43. Klappenbach JA, Dunbar JM, Schmidt TM: rRNA operon copy number reflects ecological strategies of bacteria. Appl Environ Microbiol 2000, 66: | 328-|333.

44. Moran NA, Dunbar HE, Wilcox JL: Regulation of transcription in a reduced bacterial genome: nutrient-provisioning genes of the obligate symbiont Buchnera aphidicola. J Bacteriol 2005, I 87:4229-4237.

45. Renesto P, Ogata H, Audic S, Claverie JM, Raoult D: Some lessons from Rickettsia genomics. FEMS Microbiol Rev 2005, 29:99-I 17.

46. Shigenobu S, Watanabe H, Hattori M, Sakaki Y, Ishikawa H: Genome sequence of the endocellular bacterial symbiont of aphids Buchnera sp. APS. Nature 2000, 407:8I-86.

47. Tamas I, Klasson LM, Sandstrom JP, Andersson SG: Mutualists and parasites: how to paint yourself into a (metabolic) corner. FEBS Lett 2001, 498:135-139.

48. Pugsley AP, Francetic O, Driessen AJ, Lorenzo Vde: Getting out: protein traffic in prokaryotes. Mol Microbiol 2004, 52:3-I I.

49. Foster J, Ganatra M, Kamal I, Ware J, Makarova K, Ivanova N, et al.: The Wolbachia genome of Brugia malayi: endosymbiont evolution within a human pathogenic nematode. PLOS Biol 2005, 3: el2I.

50. Achtman $M$, Wagner $M$ : Microbial diversity and the genetic nature of microbial species. Nat Rev Microbiol 2008, 6:43|-440.

51. Dobrindt U, Hochhut B, Hentschel U, Hacker J: Genomic islands in pathogenic and environmental microorganisms. Nat Rev Microbiol 2004, 2:4l4-424.

52. Pallen MJ, Wren BW: Bacterial pathogenomics. Nature 2007, 449:835-842.

53. ten Bokum AM, Movahedzadeh F, Frita R, Bancroft G], Stoker NG: The case for hypervirulence through gene deletion in Mycobacterium tuberculosis. Trends Microbiol 2008, I 6:436-44I.

54. Casali N: Hypervirulent Mycobacterium tuberculosis . In Mycobacterium genomics and molecular biology Edited by: Parish T, Brown A. Norfolk, UK: Caister Academic Press; 2009:19-34.

55. Demangel C, Stinear TP, Cole ST: Buruli ulcer: reductive evolution enhances pathogenicity of Mycobacterium ulcerans. Nat Rev Microbiol 2009, 7:50-60.

56. Stephens RS, Kalman S, Lammel C, Fan J, Marathe R, Aravind L, et al.: Genome sequence of an obligate intracellular pathogen of humans: Chlamydia trachomatis. Science 1998, 282:754-759.

57. Andersson SG, Zomorodipour A, Andersson JO, Sicheritz-Ponten T, Alsmark UC, Podowski RM, et al.: The genome sequence of Rickettsia prowazekii and the origin of mitochondria. Nature 1998, 396: I33-140

58. Schmitz-Esser S, Linka N, Collingro A, Beier CL, Neuhaus HE, Wagner $M$, et al: ATPIADP translocases: a common feature of obligate intracellular amoebal symbionts related to Chlamydiae and Rickettsiae. J Bacteriol 2004, I86:683-69I.

59. Kanehisa M, Goto S, Kawashima S, Okuno Y, Hattori M: The KEGG resource for deciphering the genome. Nucleic Acids Res 2004, 32:D277-D280.

60. Tatusov RL, Galperin MY, Natale DA, Koonin EV: The COG database: a tool for genome-scale analysis of protein functions and evolution. Nucleic Acids Res 2000, 28:33-36. 
61. Tatusov RL, Fedorova ND, Jackson JD, Jacobs AR, Kiryutin B, Koonin $\mathrm{EV}$, et al:: The COG database: an updated version includes eukaryotes. BMC Bioinformatics 2003, 4:4I.

62. Pellegrini M, Marcotte EM, Thompson MJ, Eisenberg D, Yeates TO: Assigning protein functions by comparative genome analysis: protein phylogenetic profiles. Proc Natl Acad Sci USA 1999 96:4285-4288.

63. Gower JC: Some distance properties of latent root and vestor methods used in multivariate analysis. Biometrika 1966, 53:325-338

64. Thioulouse J, Chessel D, Doléodec S, Olivier JM: Ade-4: a multivariate analysis and graphical display software. Statistics and Computing 1997, 7:75-83.

65. Schell MA, Ulrich RL, Ribot WJ, Brueggemann EE, Hines HB, Chen D, et al: Type $\mathrm{VI}$ secretion is a major virulence determinant in Burkholderia mallei. Mol Microbiol 2007, 64: | 466-| 485.

66. Moran NA: Accelerated evolution and Muller's rachet in endosymbiotic bacteria. Proc Natl Acad Sci USA 1996, 93:2873-2878

67. Wernegreen J]: Genome evolution in bacterial endosymbionts of insects. Nat Rev Genet 2002, 3:850-86I.

68. Lawrence JG: Gene transfer, speciation, and the evolution of bacterial genomes. Curr Opin Microbiol 1999, 2:519-523.

69. Ogata H, La SB, Audic S, Renesto P, Blanc G, Robert C, et al:: Genome sequence of Rickettsia bellii illuminates the role of amoebae in gene exchanges between intracellular pathogens. PLoS Genet 2006, 2:e76.

70. Ogata H, Renesto P, Audic S, Robert C, Blanc G, Fournier PE, et al:: The genome sequence of Rickettsia felis identifies the first putative conjugative plasmid in an obligate intracellular parasite. PLoS Biol 2005, 3:e248.

7I. Blanc G, Ogata H, Robert C, Audic S, Claverie JM, Raoult D: Lateral gene transfer between obligate intracellular bacteria: evidence from the Rickettsia massiliae genome. Genome Res 2007, I7:1657-1664.

72. Andersson JO, Andersson SG: Genome degradation is an ongoing process in Rickettsia. Mol Biol Evol 1999, I6: I 178-II9I.

73. Woese CR, Maniloff J, Zablen LB: Phylogenetic analysis of the mycoplasmas. Proc Natl Acad Sci USA 1980, 77:494-498.

74. Woese CR: Bacterial evolution. Microbiol Rev 1987, 5 I:22 I-27I.

75. Andersson JO, Andersson SG: Insights into the evolutionary process of genome degradation. Curr Opin Genet Dev 1999, 9:664-67I.

76. Moran NA: Tracing the evolution of gene loss in obligate bacterial symbionts. Curr Opin Microbiol 2003, 6:5 I2-5।8.

77. Mayr E: Systematics and the origin of species from the viewpoint of a zoologist New York: Columbia Univ. Press; 1942.

78. Hendry AP: Evolutionary biology: Speciation. Nature 2009 , 458:162-164.

Publish with Bio Med Central and every scientist can read your work free of charge

"BioMed Central will be the most significant development for disseminating the results of biomedical research in our lifetime. "

Sir Paul Nurse, Cancer Research UK

Your research papers will be:

- available free of charge to the entire biomedical community

- peer reviewed and published immediately upon acceptance

- cited in PubMed and archived on PubMed Central

- yours - you keep the copyright 